NIST Technical Note 2094

\title{
Effect of Fire-Retardant Coatings and Accelerated-Weathering on the Flammability of Wood-Based Materials in Wildland-Urban Interface (WUI) Communities
}

\author{
Laura Dubrulle \\ Mauro Zammarano \\ Rick D. Davis
}

This publication is available free of charge from:

https://doi.org/10.6028/NIST.TN.2094

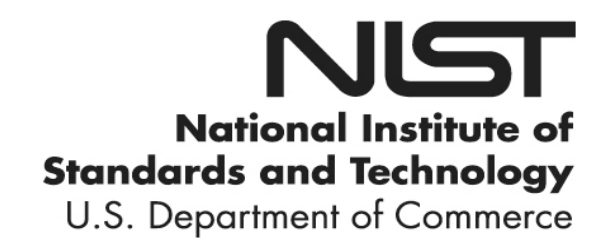


NIST Technical Note 2094

\title{
Effect of Fire-Retardant Coatings and Accelerated-Weathering on the Flammability of Wood-Based Materials in Wildland-Urban Interface (WUI) Communities
}

\author{
Laura Dubrulle \\ Mauro Zammarano \\ Rick D. Davis \\ Fire Research Division \\ Engineering Laboratory
}

This publication is available free of charge from:

https://doi.org/10.6028/NIST.TN.2094

May 2020

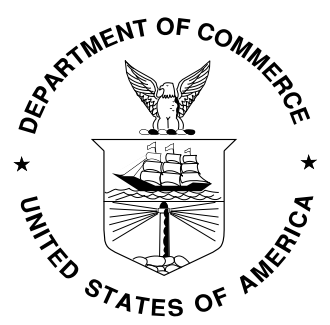

U.S. Department of Commerce Wilbur L. Ross, Jr., Secretary

National Institute of Standards and Technology Walter Copan, NIST Director and Undersecretary of Commerce for Standards and Technology 
Certain commercial entities, equipment, or materials may be identified in this document in order to describe an experimental procedure or concept adequately. Such identification is not intended to imply recommendation or endorsement by the National Institute of Standards and Technology, nor is it intended to imply that the entities, materials, or equipment are necessarily the best available for the purpose.

National Institute of Standards and Technology Technical Note 2094

Natl. Inst. Stand. Technol. Tech. Note 2094, 30 pages (May 2020) CODEN: NTNOEF

This publication is available free of charge from: https://doi.org/10.6028/NIST.TN.2094 


\begin{abstract}
A study of a limited number of commercial fire-retardant coatings (FRCs) designed for wood in outdoor applications, film-forming or non-film forming (stains), and top-coatings (used in combination with a FRC to increase its durability) were characterized by microscale combustion calorimetry (MCC) and cone calorimetry $\left(50 \mathrm{~kW} / \mathrm{m}^{2}\right)$. All coatings were applied on western red cedar and according to the manufacturers' specifications. A standard accelerated-weathering protocol alternating cycles of UV, spray, and condensation was used to evaluate the outdoor durability of the coated wood samples. Prior to accelerated-weathering, four of the FRCs showed a significant reduction on the flammability of western red cedar wood with a decrease in peak heat release rate (PHRR) and total heat release (THR). After accelerated-weathering equivalent to an estimated outdoor time of 14 days to 28 days, the cone results revealed that all FRCs became ineffective (no significant reduction in PHRR and THR of the wood substrate). The use of five top-coatings was investigated to extend the durability of FRCs. Only two dual-coated systems based on FRCs and top-coatings maintained good compatibility (no suppression of the intumescent char expansion) and fire behavior. An outdoor durability of up to seven months was estimated based on accelerated-weathering for the best FRC/top-coating combination. After this period, this dual-coated system did not show any flammability reduction by cone calorimetry.

The results of this study suggest that weathering drastically reduces the durability and fire resistance of FRCs on wood-based products.
\end{abstract}

\title{
Key words
}

Accelerated-weathering; cone calorimetry; fire-retardant coatings; microscale combustion calorimetry; top-coatings. 
Table of Contents
Abstract
.. .1
List of Tables ...................................................................................................................... iii

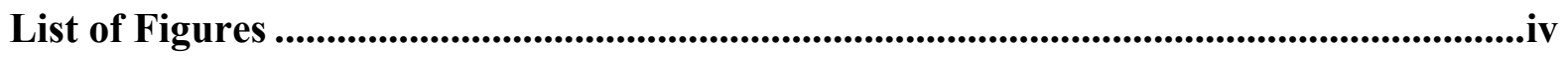

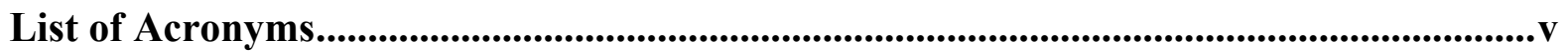

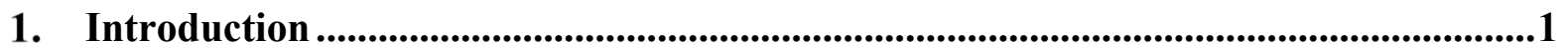

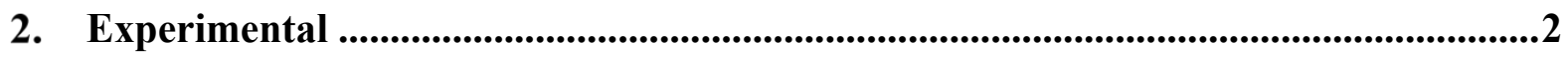

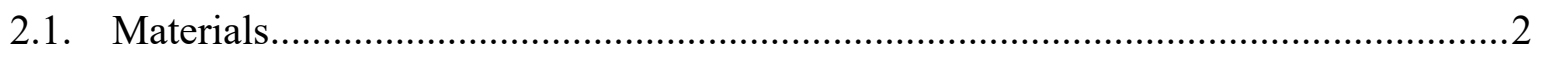

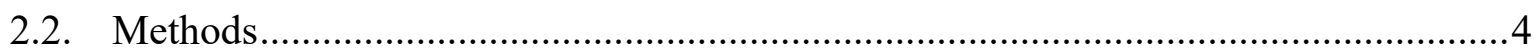

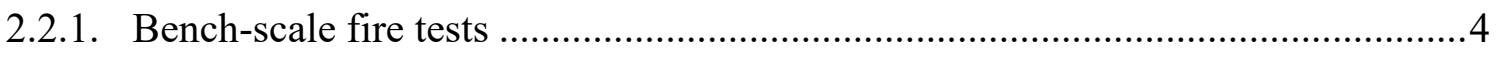
2.2.2. Rainwater solubility and accelerated-weathering tests ..................................4

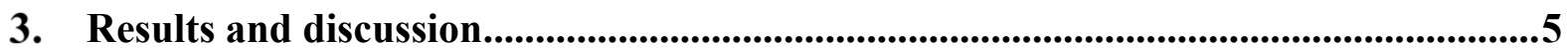

3.1. Fire performance of non-weathered fire-retardant coatings ....................................5

3.1.1. Microscale Combustion Calorimetry …..........................................................

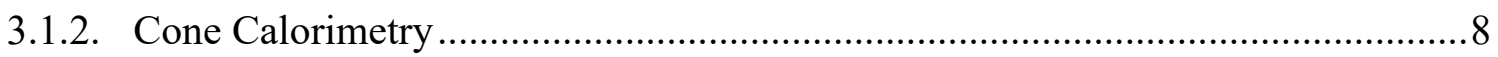

3.2. Fire performance of weathered fire-retardant coatings and top-coatings .................10

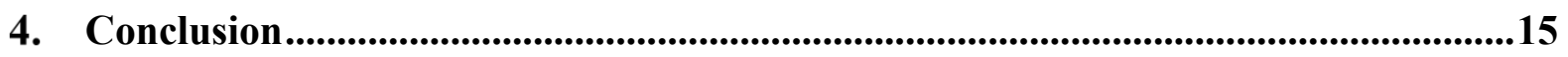

Acknowledgements ...............................................................................................................16

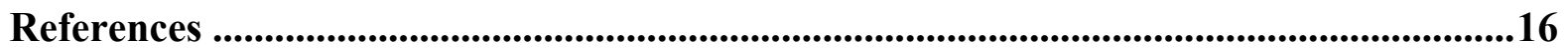

Appendix A: Supplemental Materials .......................................................................19 


\section{List of Tables}

Table 1. Physicochemical properties of fire-retardant coatings and top-coatings.................. 3

Table 2. MCC results for the commercial FRCs. ................................................................. 5

Table 3. Cone calorimetry results for commercial FRCs. .............................................. 8

Table 4. Mass loss of film-forming coatings 1, 2, 4, and 6 after $1 \mathrm{~d}, 3 \mathrm{~d}$, and $7 \mathrm{~d}$ in simulated

rainwater. 10

Table 5. Cone calorimetry results of uncoated red cedar before and after aging in the QUV.

Table 6. Cone calorimetry results of FRCs $\mathbf{1 , 2}, \mathbf{4}$, and $\mathbf{6}$ after $1 \mathrm{~d}$ and $3 \mathrm{~d}$ in the QUV.......11

Table 7. Mass loss of top-coatings A, B, C, D, and E after $1 \mathrm{~d}, 3 \mathrm{~d}$, and $7 \mathrm{~d}$ in simulated rainwater.

Table 8. Cone calorimetry results of system $\mathbf{1}+\mathbf{D}$ before and after aging in the QUV

Table 9. Cone calorimetry results of system $6+\mathbf{D}$ before and after aging in the QUV 


\section{List of Figures}

Fig. 1. HRC as a function of temperature for film-forming coatings using MCC. Each curve is a representation of each coating individually.

Fig. 2. HRC as a function of temperature for stains using MCC. Each curve is a representation of each coating individually

Fig. 3. Pictures comparing residues after MCC of: (A) intumescent film-forming coating $\mathbf{2}$, vs (B) stain 7.

Fig. 4. HRR as a function of time for film-forming coatings 1, 2, and 5 using cone calorimetry $\left(50 \mathrm{~kW} / \mathrm{m}^{2}\right)$.

Fig. 5. Aging of system $1+D$ after $28 \mathrm{~d}$ in QUV.

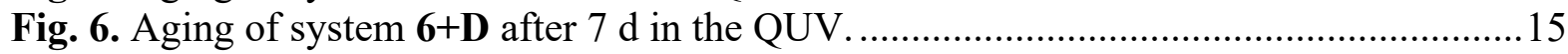

Fig. 7. HRC as a function of time for uncoated red cedar using MCC . .............................. 19

Fig. 8. HRR as a function of time for all commercial FRCs (film-forming and stains). .......20

Fig. 9. THR as a function of time for all commercial FRCs (film-forming and stains)..........21

Fig. 10. HRR as a function of time for incompatible FRC + top-coating dual-coated systems.

Fig. 11. System 2+D (left) and 1+D (right). The intumescent char expansion from FRC $\mathbf{1}$ protected the wood substrate. The incompatibility between $\mathbf{2}$ and $\mathbf{D}$ suppressed the fire protection.

Fig. 12. Intumescent char expansion $(\mathbf{2}$ - left), reduction $(\mathbf{2}+\mathbf{D}$ - middle), suppression (4+D - 


\section{List of Acronyms}

FRC

HRC

HRR

MCC

PHRR

$\mathrm{RH}$

$\mathrm{T}$

THR

$t_{\text {PHRR }}$

$T_{\text {PHRR }}$

TTFO

TTI

WUI
Fire-retardant coating

Heat release capacity $(\mathrm{J} / \mathrm{g} . \mathrm{K})$

Heat release rate $\left(\mathrm{J} / \mathrm{g}\right.$ or $\left.\mathrm{kW} / \mathrm{m}^{2}\right)$

Microscale combustion calorimetry

Peak heat release rate $\left(\mathrm{J} / \mathrm{g}\right.$ or $\left.\mathrm{kW} / \mathrm{m}^{2}\right)$

Relative humidity $\left({ }^{\circ} \mathrm{C}\right)$

Temperature $\left({ }^{\circ} \mathrm{C}\right)$

Total heat release $\left(\mathrm{kJ} / \mathrm{g}\right.$ or $\left.\mathrm{MJ} / \mathrm{m}^{2}\right)$

Time to peak heat release rate (s)

Temperature at peak heat release rate $\left({ }^{\circ} \mathrm{C}\right)$

Time to flame out (s)

Time to ignition (s)

Wildland-urban interface 


\section{Introduction}

More than 70,000 communities adjacent to wildland vegetation (Wildland Urban Interface, WUI) in the U.S. are at risk of being involved in wildfires [1]. The annualized costs of prevention, mitigation, and suppression of WUI fires in the U.S. are estimated to range from 60-238 billion dollars [2]. Experts have predicted the destructiveness and frequency of WUI fires to increase every year due to the augmentation in the number and size of WUI communities, population density, and drier/hotter weather conditions in these areas. Evidence of this increase is that, in 2017 and 2018, California experienced seven of the most destructive wildfires in the United States' history [3].

Recent WUI fire investigations, conducted by the National Institute of Standards and Technology (NIST), have revealed that embers from vegetation and structural combustible materials, such as wood and plastics, are the primary sources of ignition and fire spread within and between communities. Under strong winds (gusts up to $27 \mathrm{~m} / \mathrm{s}$ ) that are typical of WUI fire events, embers can be carried, settle, and ignite structures and vegetations kilometers away from the original fire front [4-9]. Wood fences are of particular concern for fire spread in WUI communities, because they act as (1) "fire highways" (i.e., fire travel quickly along the fence network in an urban area), and (2) "ember generators" (i.e., embers generated by the combustion of the fence can create new fire spots) [10].

Communities can take defensive actions to reduce their vulnerabilities from wildfires [11]. Longer-term mitigation strategies could include changes in land use planning, building codes and standards, and landscaping adaptations [12, 13]. Some examples of these long-term strategies involve clustering homes, multiplying defensible spaces, creating points for emergency access and trails between vegetation and structures to act as a fuel breaker [14]. Shorter-term mitigation strategies can include hardening structures (reducing corners on roofs, distancing fences or sheds from the house, etc.) to resist WUI fires [15]. Some examples of these short-term strategies could comprise of protecting structures from ignition and decreasing fire spread within a community. The short-term mitigation approaches can be divided into active (e.g., extinguishers and sprinklers) and passive (e.g., pre-applied water, gel, or foam wetting agents or fire resistance coating and composite layers) fire protection methods [16, 17].

Fire-retardant coatings (FRCs) used in this study can be divided into two distinct categories: film-forming (paints) and non-film forming (stains) coatings. The film-forming FRCs were all intumescent, forming a foamed char when decomposing. The use of either presents several advantages over other hardening techniques such as better appearance, affordable prices, and a simple application process. On the other hand, they can have poor weathering and mold resistance [18]. Intumescent coatings are thermal-resistant materials which in the case of a fire (exposed to a heat source) can expand 20 to 50 times their initial thickness to form a carbonaceous insulating protective layer (char) on the surface of the substrate [19]. These coatings are made of three active ingredients: a carbon source (e.g., polyols such as pentaerythritol), an acid source (e.g., phosphorous compounds such as ammonium polyphosphate), and a blowing agent (e.g., melamine) [20]. As the temperature increases, the acid source decomposes and reacts with the hydroxyl groups of the carbon source to form a phosphoric ester. While the temperature continues to increase, the binder melts and the ester decomposes to form a carbon-inorganic residue. Meanwhile, by thermal decomposition, the 
blowing agent produces gas, causing the coating to expand and form an insulating layer (intumescent char) [21-23]. On the other hand, stains are designed to penetrate into the wood, which has the advantage of deeper penetration of fire retardants into the substrate. However, in order to achieve this, stains must be fluid-like, which limits the amount and type of fireretardants used in the formulation.

The current market offers many FRCs (film-forming and stain) to protect wood-based materials for outdoor applications. A few comparative studies have been performed on commercial FRCs' fire retardancy and/or weathering performances which mostly show that the weathering exposure is decreasing the effectiveness of fire protection of intumescent coatings [17, 24]. For weathering, coatings can be exposed to temperature, humidity, freezing cycles, etc. all of which can reduce the FRC's fire resistant effectiveness and service-life. A more thorough examination of the durability of FRCs and comparisons between film-forming and stain formulations have yet to be conducted.

This manuscript discusses research to understand the ability of commercial FRCs (nonweathered and weathered) to improve the fire resistance of wood commonly used in the construction of fences and decking within WUI communities. Ten commercial FRCs, either film-forming or stains for exterior application, and dual-coated wood systems comprising of FRC plus a top-coating were characterized, and their fire performance were tested using the cone calorimeter before and after weathering. An accelerated-weathering tester, known as QUV, operating with thermal, UV, and water cycling was used to accelerate weather aging of uncoated and coated wood.

\section{Experimental ${ }^{1}$}

Unless indicated, all materials were used as-received. Uncertainties are reported as $1 \sigma$ experimental standard deviations.

\subsection{Materials}

Ten FRCs (including six film-forming and four penetrating stains) made for outdoor application and five weather-resistant top-coatings were selected from the commercial market (mainly U.S.). Solid content (ASTM D2369 [25]) and wet and dry densities (ASTM D1475 [26] and ASTM D792 [27]) were characterized for all coatings to ensure proper applications (Table 1).

\footnotetext{
${ }^{1}$ The policy of NIST is to use metric units of measurement in all its publications, and to provide statements of uncertainty for all original measurements. In this document however, data from organizations outside NIST are shown, which may include measurements in non-metric units or measurements without uncertainty statements. The identification of any commercial product or trade name does not imply endorsement or recommendation by NIST. Opinions, interpretations, conclusions, and recommendations are those of the authors and are not necessarily endorsed by NIST.
} 
Table 1. Physicochemical properties of fire-retardant coatings and top-coatings. All experimental values are reported as $\bar{x} \pm 1 \sigma$ calculated from 12 measurements made from 3 replicates of the same composition.

\begin{tabular}{|c|c|c|c|c|c|c|}
\hline Coating & Composition $^{\mathrm{a}}$ & $\begin{array}{c}\text { Suggested } \\
\text { thickness } \\
(\mu \mathrm{m})\end{array}$ & $\begin{array}{c}\text { Solid } \\
\text { content } \\
(\text { mass \%) }\end{array}$ & $\begin{array}{l}\text { Wet density } \\
\qquad\left(\mathrm{g} / \mathrm{cm}^{3}\right)\end{array}$ & $\begin{array}{c}\text { Dry coating } \\
\text { density } \\
\left(\mathrm{g} / \mathrm{cm}^{3}\right)\end{array}$ & $\begin{array}{c}\text { Fire-retardant } \\
\text { chemicals }^{\mathrm{a}}\end{array}$ \\
\hline \multicolumn{7}{|c|}{ Film-forming } \\
\hline 1 & Acrylic, water-borne & 500 & $62.8 \pm 0.1$ & $1.281 \pm 0.018$ & $1.318 \pm 0.002$ & $\mathrm{~N} / \mathrm{A}$ \\
\hline 2 & Acrylic, water-borne & 325 & $61.5 \pm 0.4$ & $1.358 \pm 0.008$ & $1.502 \pm 0.009$ & $\begin{array}{c}\text { Pentaerythritol } \\
\text { Aluminum Hydroxide }\end{array}$ \\
\hline 3 & N/A, water-borne & 100 & $47.3 \pm 0.1$ & $1.238 \pm 0.011$ & $1.430 \pm 0.007$ & $\mathrm{~N} / \mathrm{A}$ \\
\hline 4 & Acrylic, solvent-borne & 270 & $75.1 \pm 0.2$ & $1.376 \pm 0.003$ & $1.662 \pm 0.026$ & Melamine \\
\hline 5 & Acrylic, water-borne & 400 & $68.4 \pm 0.5$ & $1.102 \pm 0.021$ & $1.180 \pm 0.013$ & N/A \\
\hline 6 & N/A, water-borne & 500 & $74.4 \pm 0.3$ & $1.123 \pm 0.015$ & $1.220 \pm 0.006$ & $\begin{array}{c}\text { Melamine } \\
\text { Pentaerythritol }\end{array}$ \\
\hline \multicolumn{7}{|l|}{ Stain } \\
\hline 7 & N/A, water-borne & $6 \mathrm{~m}^{2} / 1$ & $13.9 \pm 0.0$ & $1.065 \pm 0.003$ & $1.280 \pm 0.002$ & N/A \\
\hline 8 & N/A, water-borne & $6 \mathrm{~m}^{2} / 1$ & $15.3 \pm 0.1$ & $1.082 \pm 0.004$ & $1.423 \pm 0.007$ & N/A \\
\hline 9 & N/A, water-borne & $39 \mathrm{~m}^{2} / 1$ & $28.3 \pm 0.1$ & $1.136 \pm 0.003$ & $1.484 \pm 0.016$ & Phosphoric acid \\
\hline 10 & N/A, water-borne & $24 \mathrm{~m}^{2} / 1$ & $19.2 \pm 0.2$ & $1.126 \pm 0.010$ & $1.362 \pm 0.012$ & Sodium silicate \\
\hline \multicolumn{7}{|c|}{ Top-coating } \\
\hline $\mathbf{A}$ & $\begin{array}{l}\text { Two-component } \\
\text { silane-modified } \\
\text { multipolymer, } \\
\text { solvent-borne }\end{array}$ & 300 & $87.3 \pm 0.1$ & $\begin{array}{c}\text { Part } 1: \\
1.453 \pm 0.020 \\
\text { Part } 2: \\
1.024 \pm 0.012\end{array}$ & $1.133 \pm 0.014$ & \\
\hline B & $\begin{array}{c}\text { Acrylic/Urethane, } \\
\text { water-borne }\end{array}$ & $48 \mathrm{~m}^{2} / 1$ & $30.0 \pm 0.2$ & $1.051 \pm 0.007$ & $1.272 \pm 0.004$ & \\
\hline C & Acrylic, water-borne & $48 \mathrm{~m}^{2} / 1$ & $27.7 \pm 0.2$ & $1.058 \pm 0.005$ & $1.300 \pm 0.012$ & \\
\hline D & Acrylic, water-borne & 150 & $57.2 \pm 1.1$ & $1.220 \pm 0.021$ & $1.447 \pm 0.018$ & \\
\hline $\mathbf{E}$ & Acrylic, water-borne & 150 & $46.1 \pm 0.1$ & $1.261 \pm 0.012$ & $1.385 \pm 0.006$ & \\
\hline
\end{tabular}

${ }^{\text {a}}$ From the manufacturer's Safety Data Sheet.

bManufacturer's recommendation - applied in 2 coats. For some coatings, coverage rate $\left(\mathrm{m}^{2} / \mathrm{l}\right)$ is expressed instead of dry thickness.

Film-forming coatings contained higher solid contents than stains. The complete composition of the FRCs are proprietary; however, it is our understanding that all formulations do contain fire-retardant chemicals commonly used in FRCs (e.g., melamine, ammonium polyphosphate, pentaerythritol, and aluminum hydroxide).

Western red cedar lumber (The Hardwood Store of North Carolina, USA) was the substrate used in this study, since it is one of the most commonly used wood species in the U.S. for outdoor construction. Prior to coating the top surface, the wood was sanded (3M, 180 grit), and the edges were covered with tape. To reach the thickness suggested by manufacturers, the mass of applied coatings was calculated using the following formula:

$$
m=\frac{A \times t \times d}{S C}
$$


Where $m$ is the mass applied $(\mathrm{g}), A$ is the surface area of the substrate $\left(\mathrm{cm}^{2}\right), t$ is the dry film thickness of the coating $(\mathrm{cm}), d$ is the dry coating density $\left(\mathrm{g} / \mathrm{cm}^{3}\right)$, and $S C$ is the solid content of the coating (mass \%). Once the coating are dried (air dried in the fume hood), a thickness gauge (OG202, Micrometrics Co., [28]) was used to verify the thickness. Since wood is a hygroscopic material, all samples were conditioned at $\mathrm{T}=20{ }^{\circ} \mathrm{C} \pm 5{ }^{\circ} \mathrm{C}$ and $\mathrm{RH}=55 \% \pm 5 \%$ prior to cone calorimetry experiments.

\subsection{Methods}

\subsubsection{Bench-scale fire tests}

Microscale Combustion Calorimetry (MCC) was carried out on $3 \mathrm{mg}$ to $5 \mathrm{mg}$ samples (dried coating without wood substrate) using a Govmark MCC-1 [29] heated up to $750{ }^{\circ} \mathrm{C}$ at a heating rate of $1{ }^{\circ} \mathrm{C} / \mathrm{s}$ in a stream of $\mathrm{N}_{2}$ flowing at $80 \mathrm{~cm}^{3} / \mathrm{min}$. The combustor chamber temperature and $\mathrm{O}_{2} / \mathrm{N}_{2}$ flow rate were set up respectively at $900{ }^{\circ} \mathrm{C}$ and $20 / 80 \mathrm{~cm}^{3} / \mathrm{min}$. One particular feature is to decouple pyrolysis and combustion which separately reproduces the solid and gas phase processes of flaming combustion in a non-flaming test [30]. The decomposition of the condensed phase occurred under anaerobic conditions $\left(\mathrm{N}_{2}\right)$, before gases released from pyrolysis were sent to the combustion chamber. Gases were then burnt to complete combustion and oxygen was consumed. The amount of char residue was calculated by determining the mass of the sample before and after testing. Reported results are the average of three measurements of each sample with a relative error up to $\pm 10 \%$.

A cone calorimeter (Fire Testing Technology, UK, [31]) was used to measure ignition characteristics, heat release rate, total heat release and sample mass loss according to ASTM E1354 [32]. An external heat flux of $50 \mathrm{~kW} / \mathrm{m}^{2} \pm 0.5 \mathrm{~kW} / \mathrm{m}^{2}$ was applied. An electric spark igniter was used as the ignition source. All samples (nominal dimensions of $100 \mathrm{~mm}$ by 100 $\mathrm{mm}$ by $13 \mathrm{~mm}$ ) were tested in the horizontal position and wrapped with aluminum foil (except for the exposed surface) and were then laid on a holder with a ceramic wool blanket. A standard retainer frame, as described by ASTM E1354, was also used to contain the samples and reduce unrepresentative edge burning of specimens; resulting in an exposed surface area of $88.4 \mathrm{~cm}^{2}$. Since intumescent coatings were tested, the distance between the surface of the sample and the cone was increased from $25 \mathrm{~mm}$ to $60 \mathrm{~mm}$ (according to ASTM E1354) to prevent contact of the swelling material with the underside of the cone heater and spark igniter. A methane burner with an output of $5 \mathrm{~kW}$ was used to calibrate the cone calorimeter, with the determination of the orifice plate mass flow meter, also called the C-factor. Reported results are the average of three measurements of each sample with a relative error up to $\pm 10 \%$.

\subsubsection{Rainwater solubility and accelerated-weathering tests}

Preliminary tests were conducted to assess the solubility of coatings in simulated rainwater according to ASTM D3132 [33]. The simulated rainwater was synthesized according to the National Institute of Standards and Technology procedure (Standard Reference Materials No. 2694 [34]). Silicone molds were used to make disks of coatings (thickness $=800 \mu \mathrm{m}$, diameter $=25 \mathrm{~mm})$. The coating disks were placed in plastic containers $(\mathrm{V}=20 \mathrm{~mL})$ and synthetic rainwater was added with a 1 to 10 mass ratio of coating to rainwater. The containers were attached to the sample holders of a rotator (Tissue Culture Rotator Drum-X L-85, Elmeco Laboratory Instruments) set at $6.3 \mathrm{rad} / \mathrm{s}$. The mass of each sample was measured after $1 \mathrm{~d}, 3 \mathrm{~d}$, and $7 \mathrm{~d}$, after drying the disks in the oven at $100{ }^{\circ} \mathrm{C}$ for $1 \mathrm{~h}$. Reported results are the average of three mass loss measurements for each coating. 
To assess the aging of coatings, coated red cedar samples (nominal dimensions of $100 \mathrm{~mm}$ by $100 \mathrm{~mm}$ by $13 \mathrm{~mm}$ ) were exposed in a QUV accelerated-weathering device (Q-Lab, USA, [35]) prior to cone calorimetry experiments. Cycle 7 of ASTM G154 [36] was followed: $8 \mathrm{~h}$ of UV exposure (UV-A 340 lamps at irradiance of $1.55 \mathrm{~W} / \mathrm{m}^{2} / \mathrm{nm}, 60{ }^{\circ} \mathrm{C}$ ), $0.25 \mathrm{~h}$ of spray (no light), $3.75 \mathrm{~h}$ of condensation $\left(50^{\circ} \mathrm{C}\right)$. This cycle was chosen to mimic the worst-case aging scenario (hot, wet, and high UV environment). Number of cycles varied depending on the accelerated-aging behavior of each sample. One cone calorimetry test was done per sample for the aging experiment.

\subsubsection{Experimental uncertainty}

Experimental results are reported as mean values and standard deviations calculated as

$$
\begin{array}{cl}
\bar{x}=\frac{\sum x}{n} & \text { mean value } \\
\sigma=\frac{\sum(x-\bar{x})^{2}}{n-1} & \text { standard deviation }
\end{array}
$$

where $x$ is the measured value, $n$ is the number of replicant measurements, $\bar{x}$ is the mean value, and $\sigma$ is the standard deviation. All data is reported as $\bar{x} \pm \sigma$. Unless otherwise indicated, $n$ is 10 .

\section{Results and discussion}

\subsection{Fire performance of non-weathered fire-retardant coatings}

3.1.1. Microscale Combustion Calorimetry

The MCC is a powerful tool to rank the flammability of polymeric materials by measuring their heat release capacity (HRC, J/g.K) [37-39]. This method was used on commercial FRCs before testing them using a complementary method such as the cone calorimeter. Other typical data from MCC experiments are peak heat release rate (PHRR, W/g), temperature at PHRR $\left(\mathrm{T}_{\mathrm{PHRR}},{ }^{\circ} \mathrm{C}\right)$, and total heat release $(\mathrm{THR}, \mathrm{kJ} / \mathrm{g})$. All MCC values are summarized in Table 2 for commercial FRCs. Fig. 1 and Fig. 2 depict the HRC as a function of temperature for respectively film-forming and stain coatings.

Table 2. MCC results for the commercial FRCs. All experimental values are reported as $\bar{x} \pm$ $1 \sigma$ calculated from 10 replicant tests. 


\begin{tabular}{lcccc}
\hline Sample & $\begin{array}{c}\text { PHRR (J/g) } \\
\text { HRC (J/g.K) }\end{array}$ & T $_{\text {PHRR }}\left({ }^{\circ} \mathbf{C}\right)$ & THR (kJ/g) & $\begin{array}{c}\text { Residue } \\
\text { (mass \%) }\end{array}$ \\
\hline Uncoated red cedar & $142 \pm 7$ & $388 \pm 4$ & $11.5 \pm 0.2$ & $14.4 \pm 0.7$ \\
\hline Film-forming & & & & \\
\hline $\mathbf{1}$ & $86 \pm 2$ & $353 \pm 1$ & $6.5 \pm 0.3$ & $45.6 \pm 1.0$ \\
$\mathbf{2}$ & $63 \pm 2$ & $352 \pm 1$ & $6.1 \pm 0.1$ & $49.8 \pm 0.2$ \\
$\mathbf{3}$ & $71 \pm 1$ & $345 \pm 3$ & $7.0 \pm 0.6$ & $39.7 \pm 2.2$ \\
$\mathbf{4}$ & $49 \pm 1$ & $390 \pm 2$ & $7.5 \pm 0.5$ & $37.4 \pm 0.5$ \\
$\mathbf{5}$ & $53 \pm 2$ & $363 \pm 6$ & $7.1 \pm 0.1$ & $30.7 \pm 1.9$ \\
$\mathbf{6}$ & $52 \pm 1$ & $361 \pm 0$ & $6.8 \pm 0.4$ & $51.4 \pm 1.0$ \\
\hline Stain & & & & \\
\hline $\mathbf{7}$ & $80 \pm 5$ & $410 \pm 2$ & $3.2 \pm 1.1$ & $68.5 \pm 0.8$ \\
$\mathbf{8}$ & $14 \pm 1$ & $184 \pm 34$ & $3.4 \pm 2.2$ & $16.9 \pm 0.5$ \\
$\mathbf{9}$ & $60 \pm 10$ & $193 \pm 7$ & $7.1 \pm 0.5$ & $35.6 \pm 0.6$ \\
$\mathbf{1 0}$ & $15 \pm 3$ & $132 \pm 1$ & $3.0 \pm 0.4$ & $69.5 \pm 0.9$ \\
\hline
\end{tabular}

${ }^{a}$ With a heating rate of $1 \mathrm{~K} / \mathrm{s}$, PHRR $=$ HRC.

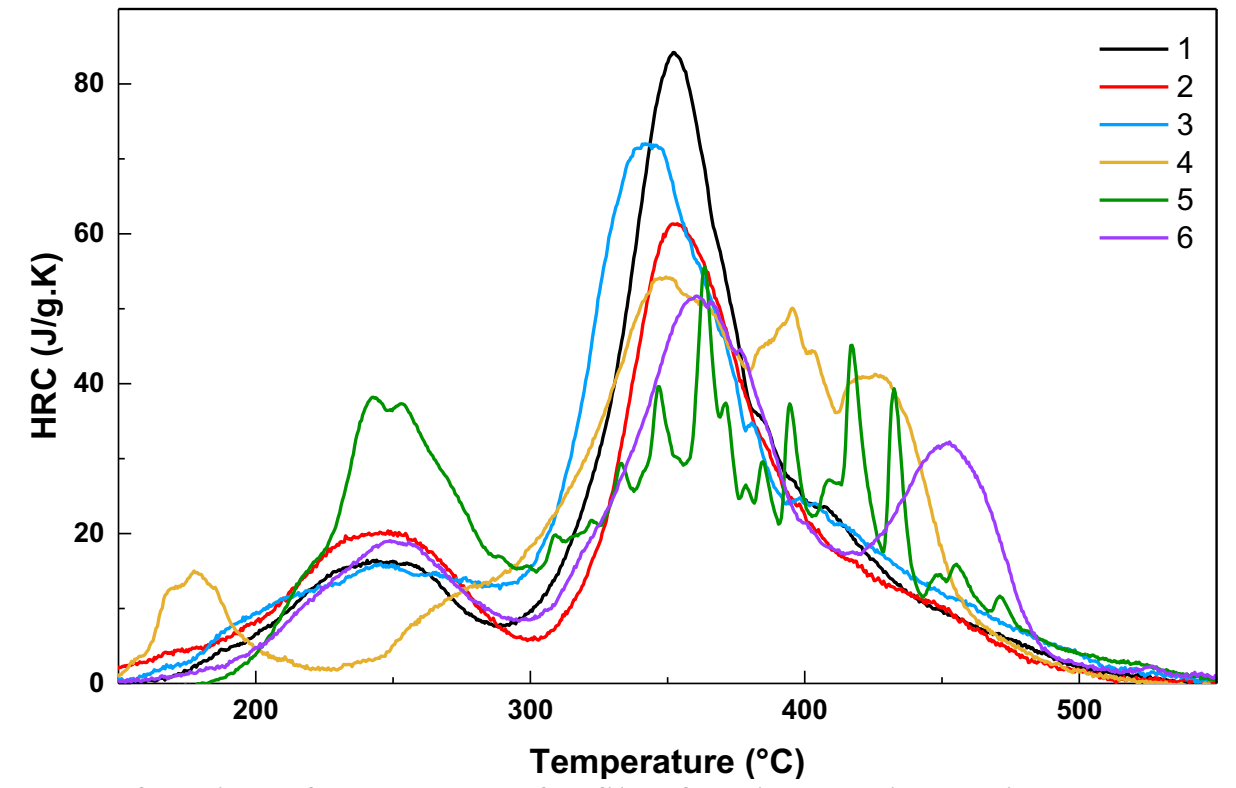

Fig. 1. HRC as a function of temperature for film-forming coatings using MCC. Each curve is a representation of each coating individually. Mean and uncertainty values are reported in Table 2. To help with viewing the data, uncertainty bars were excluded from the graphs. 


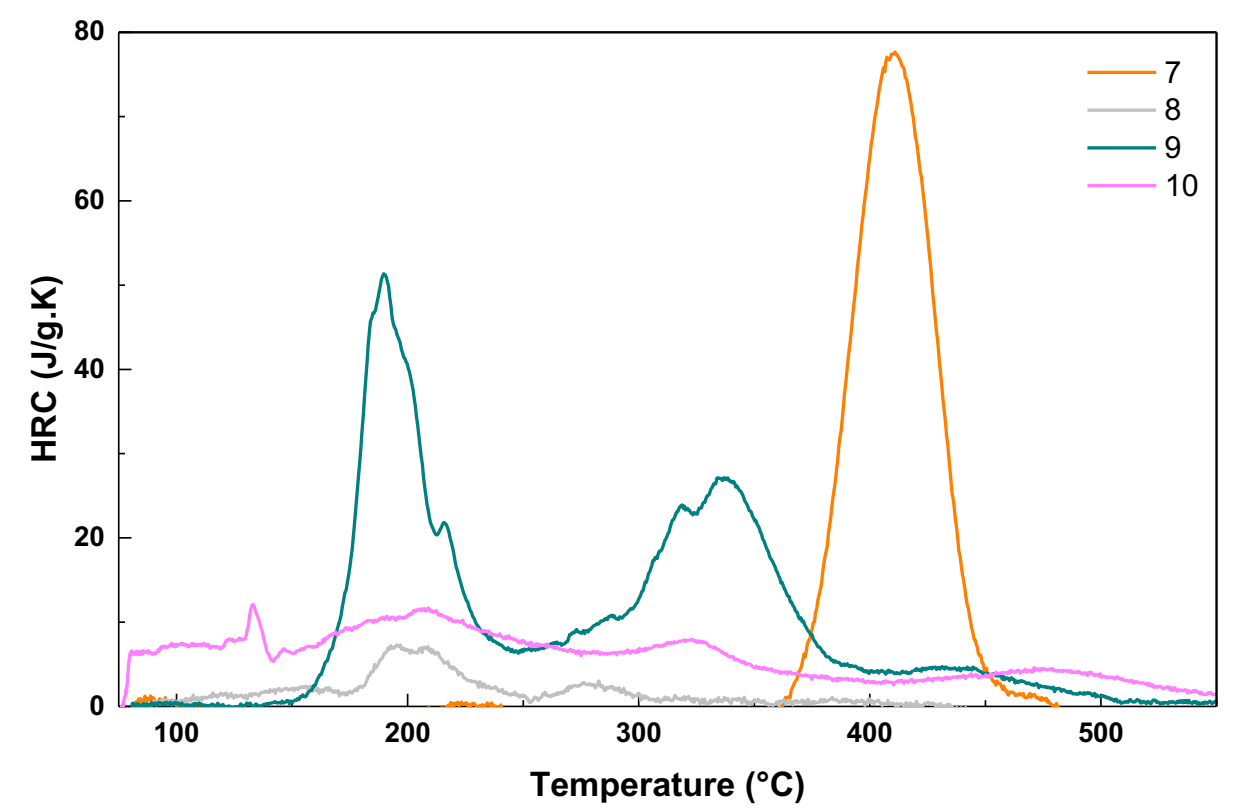

Fig. 2. HRC as a function of temperature for stains using MCC. Each curve is a representation of each coating individually. Mean and uncertainty values are reported in Table 2. To help with viewing the data, uncertainty bars were excluded from the graphs.

The first thing to notice is that all coatings have lower HRC values (reduction between $40 \%$ and $90 \%$ ) and THR values (reduction between $35 \%$ and $74 \%$ ), as compared to the control uncoated western red cedar sample (MCC curve for uncoated red cedar is reported in Appendix A: Supplemental Material). The lowest THR values were obtained with film-forming coating $2(6.1 \mathrm{~kJ} / \mathrm{g} \pm 0.1 \mathrm{~kJ} / \mathrm{g})$ and stain $10(3.0 \mathrm{~kJ} / \mathrm{g} \pm 0.4 \mathrm{~kJ} / \mathrm{g})$. The lowest $\mathrm{HRC}$ values were obtained with film-forming $4(49 \mathrm{~J} / \mathrm{g} . \mathrm{K} \pm 1 \mathrm{~J} / \mathrm{g} \cdot \mathrm{K})$ and stain $8(14 \mathrm{~J} / \mathrm{g} \cdot \mathrm{K} \pm 1 \mathrm{~J} / \mathrm{g} . \mathrm{K})$. All film-forming coatings showed intumescent properties after MCC experiments; stains did not (Fig. 3). These results suggest that film-forming coatings will provide a superior thermal barrier performance compared to the stains due to the formation of a thick insulating foam like char.

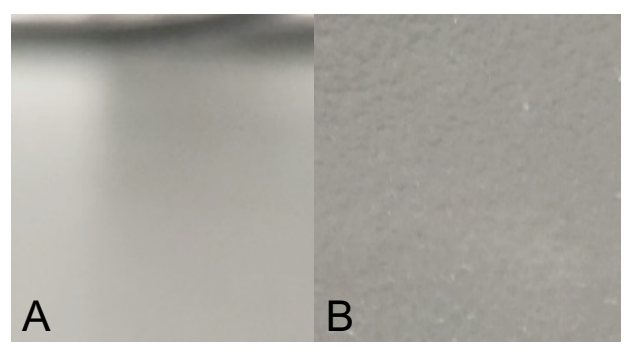

Fig. 3. Pictures comparing residues after MCC of: (A) intumescent film-forming coating $\mathbf{2}$, vs (B) stain 7.

The MCC is intended for analyzing materials with simple thermal decomposition mechanisms [40]. In this study, because of the complex mechanisms of the FRCs and the interaction with wood, the MCC is best used for a screening/relative ranking within this test series. For a more accurate measure of the FRCs performance, cone calorimetry was necessary. 


\subsubsection{Cone Calorimetry}

During a wildfire, heat transfers in three ways; conduction, convection, and radiation. This heat transfer is a major factor in the fire ignition, spread, growth, decay, and extinction [41]. To best mimic wildfire conditions, the cone calorimetry experiments were performed at $50 \mathrm{~kW} / \mathrm{m}^{2}$. Literature surveys $[42,43]$ and preliminary tests with uncoated red cedar confirmed this value to be the appropriate external heat flux. Three different ignition procedures were used based on how the sample performed:

1) When the sample ignites, the spark igniter is removed. If flame-out occurs at least $60 \mathrm{~s}$ after ignition, the data was recorded 2 min after flame-out.

2) When the sample ignites, the spark igniter is removed. If flame-out occurs within $60 \mathrm{~s}$, the spark igniter is re-inserted into position. If no ignition occurs after $2 \mathrm{~min}$, the test is stopped. If it ignites again, procedure 1) is followed.

3) When the sample does not ignite, the spark igniter is left in place up to $5 \mathrm{~min}$. If the sample ignites within $5 \mathrm{~min}$, procedures 1) or 2) is followed.

Table 3 summarizes results obtained for all commercial FRCs in terms of time to ignition (TTI, s), time to flame-out (TTFO, s), peak heat release rate $\left(\mathrm{PHRR}, \mathrm{kW} / \mathrm{m}^{2}\right)$, time to peak heat release rate ( $\left.\mathrm{t}_{\mathrm{PHR}}, \mathrm{s}\right)$, total heat release $\left(\mathrm{THR}, \mathrm{MJ} / \mathrm{m}^{2}\right)$, and residue (mass \%).

Table 3. Cone calorimetry results for commercial FRCs. All experimental values are reported as $\bar{x} \pm 1 \sigma$ calculated from 5 replicant tests.

\begin{tabular}{|c|c|c|c|c|c|c|c|c|}
\hline Sample & $\begin{array}{l}\text { TTI } \\
\text { (s) }\end{array}$ & $\begin{array}{l}\text { TTFO } \\
\text { (s) }\end{array}$ & $\begin{array}{c}1^{\text {st }} \text { PHRR } \\
\left(\mathrm{kW} / \mathrm{m}^{2}\right)\end{array}$ & $\begin{array}{c}2^{\text {nd }} \text { PHRR } \\
\left(\mathrm{kW} / \mathrm{m}^{2}\right)\end{array}$ & $\begin{array}{l}1^{\text {st }} \text { tPHRR } \\
\text { (s) }\end{array}$ & $\begin{array}{l}2^{\text {nd }} \text { tPHRR }_{\text {PH }} \\
\text { (s) }\end{array}$ & $\begin{array}{c}\text { THR } \\
\left(\mathrm{MJ} / \mathrm{m}^{2}\right)\end{array}$ & $\begin{array}{c}\text { Residue } \\
\text { (mass \%) }\end{array}$ \\
\hline Red cedar & $14 \pm 5$ & $529 \pm 38$ & $193.9 \pm 3.3$ & $162.5 \pm 1.1$ & $40 \pm 5$ & $430 \pm 24$ & $54.1 \pm 3.9$ & $19.9 \pm 0.5$ \\
\hline \multicolumn{9}{|c|}{ Film-forming } \\
\hline 1 & $14 \pm 2$ & $28 \pm 1$ & $89.5 \pm 9.6$ & N/A & $38 \pm 0$ & N/A & $1.6 \pm 0.2$ & $98.9 \pm 0.5$ \\
\hline 2 & $\mathrm{~N} / \mathrm{A}^{\mathrm{a}}$ & N/A & N/A & N/A & N/A & N/A & N/A & N/A \\
\hline 3 & $98 \pm 48$ & $917 \pm 42$ & $36.2 \pm 6.0$ & $105.4 \pm 18.4$ & $133 \pm 45$ & $640 \pm 6$ & $45.4 \pm 3.3$ & $25.9 \pm 1.5$ \\
\hline 4 & $20 \pm 3$ & $32 \pm 2$ & $136.1 \pm 7.9$ & N/A & $39 \pm 2$ & N/A & $1.9 \pm 0.2$ & $96.9 \pm 4.2$ \\
\hline 5 & $24 \pm 0$ & $730 \pm 57$ & $199.3 \pm 4.6$ & $118.9 \pm 11.2$ & $53 \pm 2$ & $519 \pm 51$ & $51.3 \pm 0.1$ & $27.3 \pm 0.6$ \\
\hline 6 & N/A & N/A & N/A & N/A & N/A & N/A & N/A & N/A \\
\hline \multicolumn{9}{|l|}{ Stain } \\
\hline 7 & $21 \pm 8$ & $596 \pm 47$ & $175.4 \pm 12.1$ & $174.6 \pm 42.2$ & $43 \pm 9$ & $450 \pm 10$ & $57.0 \pm 6.2$ & $22.0 \pm 0.3$ \\
\hline 8 & $17 \pm 4$ & $561 \pm 28$ & $167.4 \pm 16.6$ & $150.7 \pm 6.2$ & $42 \pm 5$ & $408 \pm 3$ & $52.0 \pm 2.0$ & $23.1 \pm 1.4$ \\
\hline 9 & $28 \pm 5$ & $673 \pm 21$ & $91.1 \pm 14.3$ & $103.3 \pm 20.1$ & $73 \pm 41$ & $493 \pm 27$ & $44.1 \pm 3.0$ & $28.9 \pm 1.8$ \\
\hline 10 & $16 \pm 2$ & $762 \pm 48$ & $173.1 \pm 9.7$ & $113.2 \pm 5.8$ & $37 \pm 2$ & $529 \pm 29$ & $57.7 \pm 2.2$ & $20.6 \pm 1.4$ \\
\hline
\end{tabular}

${ }^{a}$ No ignition

Fig. 4 shows the HRR profiles of uncoated red cedar, FRCs 1, 2, and 5. Each curve is an example of the three possible scenarios. All HRR curves are reported in Appendix A: Supplemental Materials. 


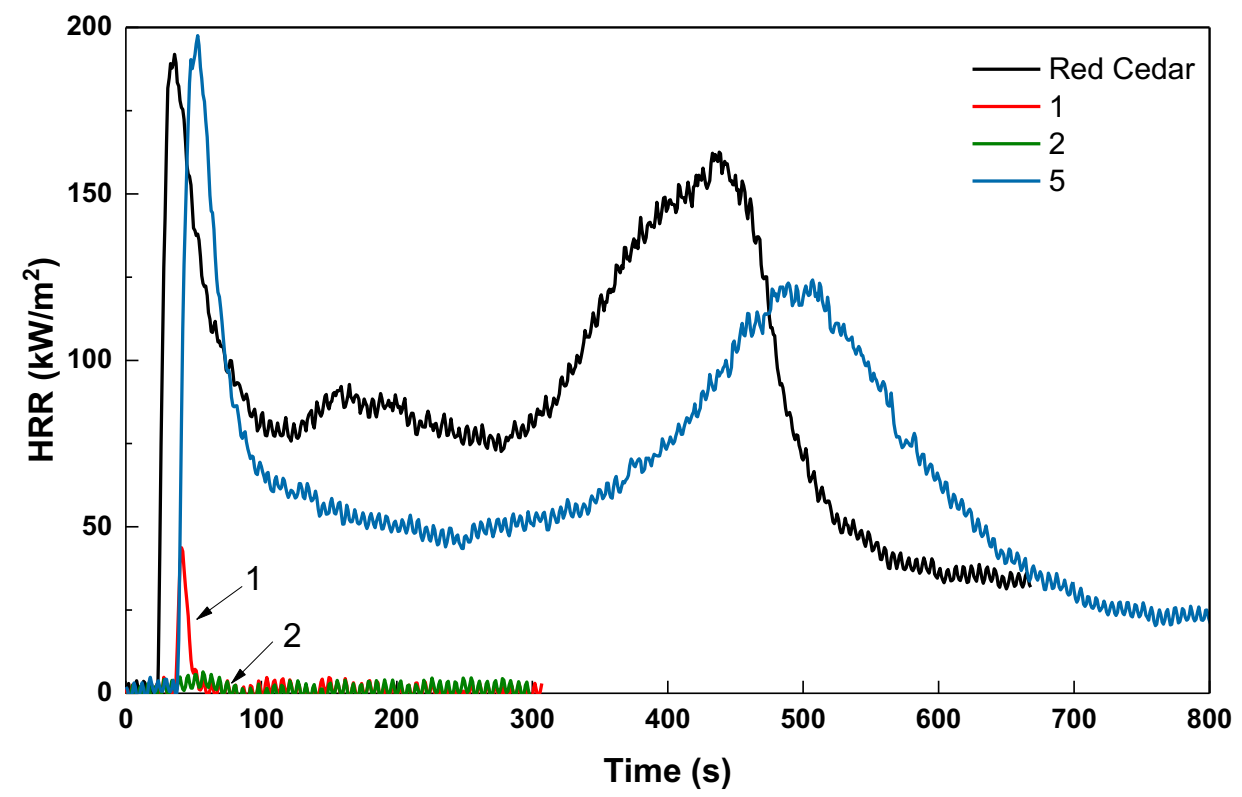

Fig. 4. HRR as a function of time for film-forming coatings 1, 2, and 5 using cone calorimetry $\left(50 \mathrm{~kW} / \mathrm{m}^{2}\right)$. Mean and uncertainty values are reported in Table 3 . To help with viewing the data, uncertainty bars were excluded from the graphs.

As previously stated, cone calorimetry results for commercial FRCs showed three different scenarios. Film-forming 3 and 5, and all stains (7, 8, 9, and 10) HRR curves all showed a two peak profile that appears to be specific to thick char forming substances [44]. At the beginning of burning, curves showed a sharp peak when the protective char builds up, corresponding to the $1^{\text {st }}$ PHRR. The apparition of a $2^{\text {nd }}$ PHRR after a minimum of 400 seconds, coincides to the further decomposition and cracking of the char. After flame-out, the samples showed afterglowing caused by the oxidative decomposition of the char resulting to a decrease of the HRR values. Their values of THR, PHRR, and residue (Table 3) are all similar to the measured values of uncoated red cedar. Results suggest that under these conditions, these coatings do not provide any significant flame-retardant properties to the wood.

For film-forming coatings 1 and 4, however, they ignited but rapidly self-extinguished (within $15 \mathrm{~s}$ ) due to the expansion of the protective intumescent char of the coating and did not ignite again after reapplying the spark igniter. Therefore, as compared to uncoated red cedar wood, their THR and PHRR values decreased drastically by an average of $98 \%$ and $51 \%$, respectively. Film-forming coatings 2 and $\mathbf{6}$ did not ignite after continuous exposure of 5 min. All film-forming coatings 1, 2, 4, and $\mathbf{6}$ showed better intumescent properties compared to other tested FRCs.

Surprisingly, six out of the ten commercial FRCs, which claimed to be fire-retardant, ignited and showed high PHRR and THR values, as comparable to the uncoated red cedar wood. In the fire scenario we chose to be closer to real wildfires conditions (heat flux at $50 \mathrm{~kW} / \mathrm{m}^{2}$ ), these FRCs did not show a significant effect. However, under different conditions, such as flame piloted ignition at lower external heat fluxes, it is reasonable to assume these FRCs may behave differently. 
Film-forming coatings 1, 2, 4, and $\mathbf{6}$ were believed to be the most promising FRCs; therefore, their weathering performance was evaluated.

\subsection{Fire performance of weathered fire-retardant coatings and top-coatings}

Prior to QUV testing, commercial FRCs 1, 2, 4, and $\mathbf{6}$ were subjected to simulated rainwater solubility tests. Table 4 summarizes the mass loss of the coating disks after $1 \mathrm{~d}, 3 \mathrm{~d}$, and $7 \mathrm{~d}$ in rainwater.

Table 4. Mass loss of film-forming coatings 1, 2, 4, and 6 after $1 \mathrm{~d}, 3 \mathrm{~d}$, and $7 \mathrm{~d}$ in simulated rainwater. All experimental values are reported as $\bar{x} \pm 1 \sigma$ calculated from 12 measurements made from 6 replicates of the same composition.

\begin{tabular}{lccc}
\hline Coating & \multicolumn{3}{c}{ Mass loss (mass \%) } \\
disk & $\mathbf{t ~}_{\mathbf{~} \text { d }}$ & $\mathbf{t}_{\mathbf{3 ~ d}}$ & $\mathbf{t}_{\mathbf{7 ~ d}}$ \\
\hline $\mathbf{1}$ & $19.0 \pm 0.1$ & $19.8 \pm 0.2$ & $21.3 \pm 0.1$ \\
$\mathbf{2}$ & $30.2 \pm 0.1$ & $31.6 \pm 0.2$ & $35.2 \pm 1.0$ \\
$\mathbf{4}$ & $10.1 \pm 0.8$ & $16.1 \pm 1.1$ & $20.1 \pm 1.6$ \\
$\mathbf{6}$ & $24.0 \pm 0.7$ & $26.1 \pm 0.9$ & $26.5 \pm 0.7$ \\
\hline
\end{tabular}

After $1 \mathrm{~d}$ in the simulated rainwater, significant mass loss was observed for all four FRCs. The lowest and highest 1-d mass loss was measured for film-forming coating 4 (10.1 mass \% \pm 0.8 mass $\%)$ and film-forming coating 2 (30.2 mass $\% \pm 0.1$ mass $\%)$. Over the remaining days, continued mass loss was measured for all FRCs but not at the same rate as observed within the first day. After $7 \mathrm{~d}$, the ranking of the FRCs according to mass loss is 4 (20.1 mass \% 1.6 mass $\%), \mathbf{1}(21.3$ mass $\% \pm 0.1$ mass $\%), 6(26.5$ mass $\% \pm 0.7$ mass $\%)$, and $2(35.2$ mass $\%$ \pm 1.0 mass \%). For film-forming 1, 2, and 6 most of the mass loss occurred during the first day, whereas the mass loss from coating $\mathbf{4}$ was more gradual.

A key take-away from these simulated rainwater experiments may be that $1 \mathrm{~d}$ appears to be enough for screening out technologies. However, longer exposures associated with UV, using the accelerated-weathering QUV device, may be necessary to adequately evaluate the servicelife performance of the technology.

To test the weatherability and long-term flame-retardant efficacy of these coatings, coated samples were placed in the QUV for up to 28 days. Samples were removed periodically and burnt in the cone calorimeter to measure the flammability. Table 5 shows the cone calorimetry data of the uncoated western red cedar with up to 28 days in the QUV. Results showed that no significant difference can be made in terms of TTI, TTFO, PHRR, and THR values. Only visual observations showed wood discoloration and cracking after one week.

Table 5. Cone calorimetry results of uncoated red cedar before and after aging in the QUV. The $\mathrm{t}_{0} \mathrm{~d}$ values are reported as $\bar{x} \pm 1 \sigma$ calculated from 12 replicant measurements from 6 samples. All values reported after $\mathrm{t}_{0 \mathrm{~d}}$ are from testing of a single sample. 


\begin{tabular}{|c|c|c|c|c|c|c|c|c|}
\hline Sample & $\begin{array}{l}\text { TTI } \\
\text { (s) }\end{array}$ & $\begin{array}{c}\text { TTFO } \\
\text { (s) }\end{array}$ & $\begin{array}{c}1^{\text {st }} \text { PHRR } \\
\left(\mathrm{kW} / \mathrm{m}^{2}\right)\end{array}$ & $\begin{array}{c}2^{\text {nd }} \text { PHRR } \\
\left(\mathrm{kW} / \mathrm{m}^{2}\right)\end{array}$ & $\begin{array}{l}1^{\text {st }} \text { tPHRR }_{\text {p }} \\
\text { (s) }\end{array}$ & $\begin{array}{l}2^{\text {nd }} \text { tPHRR }_{\text {pon }} \\
\text { (s) }\end{array}$ & $\begin{array}{c}\text { THR } \\
\left(\mathbf{M J} / \mathrm{m}^{2}\right)\end{array}$ & $\begin{array}{c}\text { Residue } \\
\text { (mass \%) }\end{array}$ \\
\hline$t_{0 d}$ & $14 \pm 5$ & $529 \pm 38$ & $193.9 \pm 3.3$ & $162.5 \pm 1.1$ & $40 \pm 5$ & $430 \pm 24$ & $54.1 \pm 3.9$ & $19.9 \pm 0.5$ \\
\hline $\mathbf{t}_{1 \mathrm{~d}}$ & 14 & 532 & 185.5 & 152.0 & 40 & 410 & 52.8 & 19.8 \\
\hline $\mathbf{t}_{3 \mathrm{~d}}$ & 16 & 553 & 182.9 & 145.3 & 39 & 395 & 51.6 & 20.8 \\
\hline $\mathbf{t}_{7 \mathrm{~d}}$ & 16 & 550 & 190.1 & 150.5 & 39 & 421 & 52.2 & 20.1 \\
\hline $\mathbf{t}_{14 \mathrm{~d}}$ & 15 & 540 & 188.3 & 160.1 & 40 & 418 & 50.8 & 19.7 \\
\hline$t_{28 d}$ & 14 & 538 & 189.8 & 155.8 & 39 & 405 & 54.0 & 20.2 \\
\hline
\end{tabular}

Table 6 shows cone calorimetry results before and after aging in the QUV for film-forming coatings 1, 2, 4, and 6. The QUV exposure time was gradually increased until the coated samples did not show significant reduction in terms of TTI, TTFO, PHRR, and THR as compared to uncoated red cedar.

Table 6. Cone calorimetry results of FRCs 1, 2, 4, and 6 after $1 \mathrm{~d}$ and $3 \mathrm{~d}$ in the QUV. All values are from testing of a single sample.

\begin{tabular}{|c|c|c|c|c|c|c|c|c|}
\hline Sample & $\begin{array}{l}\text { TTI } \\
\text { (s) }\end{array}$ & $\begin{array}{c}\text { TTFO } \\
\text { (s) }\end{array}$ & $\begin{array}{c}\text { 1 }^{\text {st }} \text { PHRR } \\
\left(\mathrm{kW} / \mathrm{m}^{2}\right)\end{array}$ & $\begin{array}{c}2^{\text {nd }} \text { PHRR } \\
\left(\mathrm{kW} / \mathrm{m}^{2}\right)\end{array}$ & $\begin{array}{l}1^{1^{\text {st }} \text { tPHRR }} \\
\text { (s) }\end{array}$ & $\begin{array}{l}2^{\text {nd }} \text { tPHRR } \\
\text { (s) }\end{array}$ & $\begin{array}{c}\text { THR } \\
\left(\mathrm{MJ} / \mathrm{m}^{2}\right)\end{array}$ & $\begin{array}{c}\text { Residue } \\
\text { (mass \%) }\end{array}$ \\
\hline \multicolumn{9}{|c|}{ Coating 1} \\
\hline$t_{0 d}$ & 14 & 28 & 89.5 & N/A & 38 & N/A & 1.6 & 98.9 \\
\hline$t_{1 d}$ & 33 & 990 & 126.7 & 122.5 & 56 & 725 & 67.9 & 26.6 \\
\hline$t_{3 d}$ & 24 & 813 & 209.0 & 151.5 & 48 & 647 & 68.1 & 27.8 \\
\hline \multicolumn{9}{|c|}{ Coating 2} \\
\hline$t_{0 d}$ & $\mathrm{~N} / \mathrm{A}^{\mathrm{a}}$ & N/A & N/A & N/A & N/A & N/A & N/A & N/A \\
\hline$t_{1 d}$ & 24 & 674 & 182.7 & 160.9 & 27 & 481 & 56.7 & 27.6 \\
\hline$t_{3 d}$ & 25 & 761 & 245.0 & 102.0 & 47 & 537 & 55.0 & 25.0 \\
\hline \multicolumn{9}{|c|}{ Coating 4} \\
\hline$t_{0 d}$ & 20 & 32 & 136.1 & N/A & 39 & N/A & 1.9 & 96.9 \\
\hline $\mathbf{t}_{1 \mathrm{~d}}$ & 17 & 40 & 89.5 & N/A & 37 & N/A & 1.3 & 98.0 \\
\hline $\mathbf{t}_{3 \mathrm{~d}}$ & $18-120^{\mathrm{b}}$ & $32-1001$ & 127.2 & 107.2 & 39 & 660 & 50.7 & 23.3 \\
\hline \multicolumn{9}{|c|}{ Coating 6} \\
\hline$t_{0 d}$ & N/A & N/A & N/A & N/A & N/A & N/A & N/A & N/A \\
\hline $\mathbf{t}_{1 \mathrm{~d}}$ & 123 & 920 & 96.5 & 145.5 & 155 & 646 & 63.5 & 33.7 \\
\hline$t_{3 d}$ & 26 & 824 & 163.7 & 145.9 & 52 & 662 & 59.7 & 23.6 \\
\hline
\end{tabular}

${ }^{\mathrm{a}}$ No ignition

${ }^{\mathrm{b}}$ Sample self-extinguishes after $32 \mathrm{~s}$ and then ignites again at $120 \mathrm{~s}$.

Coatings 1, 2, and 6 lost their fire-retardant properties only after $1 \mathrm{~d}$ in the QUV. Similar observations were made with coating 4 after $3 \mathrm{~d}$. Indeed, all values are close to the ones obtained with weathered uncoated red cedar as shown in Table 5. 
Even if the relationship between accelerated-weathering exposure and outdoor exposure depends on multiple variables such as altitude, variation of weather, orientation, literature suggests a correlation factor of about 10, meaning $1 \mathrm{~d}$ in the QUV correlates to about $10 \mathrm{~d}$ in an outdoor environment $[45,46]$. These commercial FRCs showed unsatisfied weathering resistance by losing their fire-retardant properties only for a few weeks in exterior conditions.

Rather than evaluating other FRCs or modifying the formulations of the existing ones, another approach was used; a top-coating that reduces the weathering deterioration of the FRCs was applied on top of the coated samples. There are a few concerns with using a weather-resistant top-coating: it adds a step in the application process, it requires tailoring the FRC and topcoating chemistries in order to have long-term adhesion, the top-coating may inhibit the fire retarding mechanism of the FRC, and it may contribute to the flammability of the product. While these are all reasonable concerns, for the purpose of this study, we decided to evaluate the potential of five commercial top-coatings to improve weatherability without reducing the fire resistance of selected FRCs.

The first step was to understand the viability of using top-coatings to reduce the deterioration of FRCs. Five different top-coating disks $(\mathbf{A}, \mathbf{B}, \mathbf{C}, \mathbf{D}$, and $\mathbf{E})$ were firstly soaked in the simulated rainwater for seven days (Table 7).

Table 7. Mass loss of top-coatings A, B, C, D, and $\mathbf{E}$ after $1 \mathrm{~d}, 3 \mathrm{~d}$, and $7 \mathrm{~d}$ in simulated rainwater. All experimental values are reported as $\bar{x} \pm 1 \sigma$ calculated from 12 measurements made from 6 replicates of the same composition.

\begin{tabular}{lccc}
\hline \multirow{2}{*}{ Top-coating } & \multicolumn{3}{c}{ Mass loss (mass \%) } \\
& $\mathbf{t}_{\mathbf{1 ~ d}}$ & $\mathbf{t}_{\mathbf{3 ~ d}}$ & $\mathbf{t}_{\mathbf{7 ~ d}}$ \\
\hline $\mathbf{A}$ & $1.1 \pm 0.1$ & $2.3 \pm 0.1$ & $3.1 \pm 0.1$ \\
$\mathbf{B}$ & $13.5 \pm 0.3$ & $14.7 \pm 0.6$ & $14.8 \pm 0.6$ \\
$\mathbf{C}$ & $6.5 \pm 3.7$ & $15.6 \pm 6.6$ & $26.0 \pm 8.7^{\mathrm{a}}$ \\
$\mathbf{D}$ & $1.6 \pm 0.4$ & $2.3 \pm 0.1$ & $2.9 \pm 0.1$ \\
E & $7.9 \pm 0.2$ & $8.6 \pm 0.3$ & $9.1 \pm 0.3$ \\
\hline
\end{tabular}

${ }^{\text {a}} \mathrm{High}$ values of standard deviation due to the fragmentation of the coating disk.

Top-coatings showed lower mass loss after $7 \mathrm{~d}$ in simulated rainwater than the FRCs (see Table 4). Though some of them, namely $\mathbf{B}, \mathbf{C}$, and $\mathbf{E}$ still showed high mass loss values of respectively 14.8 mass $\%$ ( \pm 0.6 mass $\%), 26.0$ mass $\%$ ( \pm 8.7 mass $\%)$, and 9.1 mass $\%$ $( \pm 0.3$ mass \%). The coating disk of top-coating $\mathbf{C}$ even fragmented over time, which resulted in very high mass loss. The best performing top-coatings were $\mathbf{A}$ and $\mathbf{D}$ with a mass loss of 3.1 mass $\%( \pm 0.1$ mass $\%)$ and 2.9 mass $\%( \pm 0.1$ mass $\%)$ after $7 \mathrm{~d}$ in rainwater compared to a loss of 20.1 mass $\%$ ( \pm 1.6 mass $\%$ ) for the best FRC (film-forming 4 ). Based on these results, top-coatings $\mathbf{A}$ and $\mathbf{D}$ were selected for further testing.

As previously stated, one concern with applying top-coating is that it can inhibit the fire retarding mechanism of FRCs. The next step was to evaluate compatibility in terms of fire performance between these two types of coatings by running cone calorimetry experiments on eight dual-coated systems (top-coatings $\mathbf{A}$ and $\mathbf{D}$ applied on FRCs 1, 2, 4, and 6). Cone calorimetry and MCC tests of top-coating $\mathbf{A}$ associated with all tested FRCs (1, 2, 4, and 6); 
and top-coating D associated with FRCs $\mathbf{2}$ and $\mathbf{4}$ revealed a change of fire behavior especially with a decrease or suppression of the intumescent expansion (see more details in Appendix A: supplemental Materials). This issue has been previously stated with the observation of a reduction of the char expansion ratio, the modification of its morphology, and a larger effective thermal conductivity of the intumescent coating with a topcoat [47-49].

Only systems with top-coating D applied on top of FRCs $\mathbf{1}$ or $\mathbf{6}$ were compatible. It should be noted that top-coating $\mathbf{D}$ was developed to work with fire-retardant coating $\mathbf{1}$.

The first dual-coated system to be tested was $\mathbf{1 + D}$ using the cone calorimeter before and after aging experiments in the QUV device for 28 days (Table 8).

Table 8. Cone calorimetry results of system 1+D before and after aging in the QUV. The Sample 1 and Sample D values are reported as $\bar{x} \pm 1 \sigma$ calculated from 10 replicant measurements from 5 samples. All other values are from testing of a single sample.

\begin{tabular}{|c|c|c|c|c|c|c|c|c|}
\hline Sample & $\begin{array}{l}\text { TTI } \\
\text { (s) }\end{array}$ & $\begin{array}{l}\text { TTFO } \\
\text { (s) }\end{array}$ & $\begin{array}{c}1^{\text {st }} \text { PHRR } \\
\left(\mathrm{kW} / \mathrm{m}^{2}\right)\end{array}$ & $\begin{array}{c}2^{\text {nd }} \text { PHRR } \\
\left(\mathrm{kW} / \mathrm{m}^{2}\right)\end{array}$ & $\begin{array}{l}1^{\text {st }} \text { tPHRR } \\
\text { (s) }\end{array}$ & $\begin{array}{l}2^{\text {nd }} \text { tPHRR } \\
\text { (s) }\end{array}$ & $\begin{array}{c}\text { THR } \\
\left(\mathbf{M J} / \mathrm{m}^{2}\right)\end{array}$ & $\begin{array}{c}\text { Residue } \\
\text { (mass \%) }\end{array}$ \\
\hline 1 & $14 \pm 2$ & $28 \pm 1$ & $89.5 \pm 9.6$ & $\mathrm{~N} / \mathrm{A}$ & $38 \pm 0$ & $\mathrm{~N} / \mathrm{A}$ & $1.6 \pm 0.2$ & $98.9 \pm 0.5$ \\
\hline D & $20 \pm 1$ & $678 \pm 35$ & $338.4 \pm 2.7$ & $131.1 \pm 5.2$ & $44 \pm 0$ & $496 \pm 13$ & $57.2 \pm 2.8$ & $23.8 \pm 1.1$ \\
\hline \multicolumn{9}{|l|}{ 1+D } \\
\hline$t_{0 d}$ & 21 & 65 & 221.2 & N/A & 49 & N/A & 5.5 & 95.7 \\
\hline $\mathbf{t}_{1 \mathrm{~d}}$ & 26 & 68 & 214.2 & N/A & 51 & N/A & 5.3 & 95.7 \\
\hline $\mathbf{t}_{3 \mathrm{~d}}$ & 24 & 68 & 203.2 & N/A & 47 & N/A & 5.0 & 95.8 \\
\hline$t_{7 d}$ & 25 & 77 & 182.9 & N/A & 47 & N/A & 5.2 & 95.2 \\
\hline $\mathbf{t}_{14 \mathrm{~d}}$ & 34 & 76 & 202.8 & N/A & 58 & N/A & 5.3 & 95.9 \\
\hline$t_{28 d}$ & 27 & 787 & 260.2 & 130.1 & 54 & 588 & 57.8 & 29.5 \\
\hline
\end{tabular}

Data on top-coating $\mathbf{D}$ itself show slightly similar flame behavior compared to uncoated red cedar (Table 5). The only difference being the $1^{\text {st }}$ PHRR, which is $75 \%$ higher than bare wood. This can be explained by the acrylic nature of this coating, which represents additional fuel.

However, the use of top-coating $\mathbf{D}$ with FRC $1,(\mathbf{1}+\mathbf{D})_{0}$ d, presents good results in terms of coatings compatibility and flaming behavior. Although the $1^{\text {st }}$ PHRR is higher, due to the layer of acrylic fuel, the intumescent expansion of coating 1 provides self-extinguishment within $44 \mathrm{~s}$. This also explains the relatively small value of THR (around $5 \mathrm{MJ} / \mathrm{m}^{2}$ ). Those observations remain the same after $14 \mathrm{~d}$ of accelerated-weathering experiments in the QUV. Though, regarding the visual aspect of the coating surface (Fig. 5), modifications in terms of yellowing began to appear. Despite their notable resistance to environmental deterioration, acrylic coatings can sometimes suffer from photodegradation via UV radiation absorption. This phenomenon creates small carbonyl chromophore molecules (e.g. ketones) and radicals through Norrish type I and II reactions which promote early material failure (loss of mechanical properties and worsening of visual assets) [50-52]. After $28 \mathrm{~d}$ in the QUV, visual observations (Fig. 5) showed more cracking and blistering/bubbling at the sample surface but also on the edges where the coating was peeling off of the substrate which may have resulted from water infiltration. Not surprisingly then, fire behavior drastically changed after $28 \mathrm{~d}$ in the QUV. The 
sample ignited, but this time burned almost for $800 \mathrm{~s}$, and results in terms of PHRR and THR were similar to uncoated red cedar (Table 5).

The system 1+D lasted between (14 and 28) days in the accelerated-weathering QUV device. Even if it is impossible to have a perfect correlation between accelerated and natural weathering due to climate differences, it has been assumed based on the literature $[45,46]$ and comparison between natural and accelerated-weathering tests [53] that the program used (cycle 7 ASTM G154) should correspond to a humid subtropical climate (e.g. Florida) and be 10 times accelerated. Based on this correlation, 1+D system would last outside for about seven months in humid subtropical conditions.

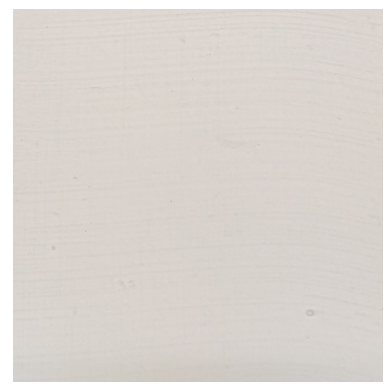

$\mathrm{t}_{0 \mathrm{~d}}$

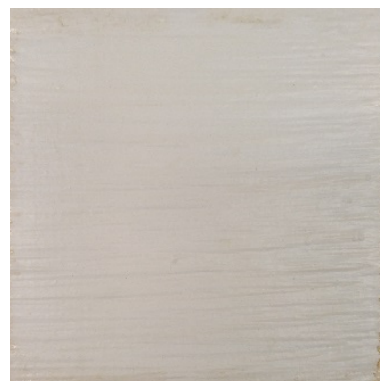

$\mathrm{t}_{1 \mathrm{~d}}$

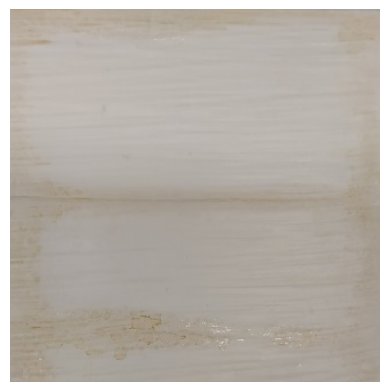

$\mathrm{t} 14 \mathrm{~d}$

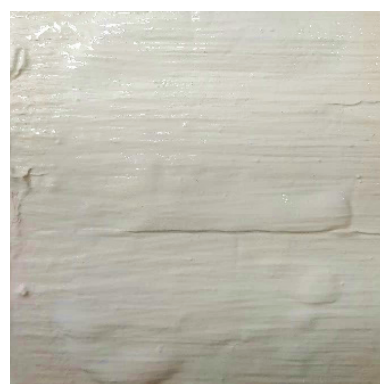

$\mathrm{t} 28 \mathrm{~d}$

Fig. 5. Aging of system $\mathbf{1}+\mathbf{D}$ after $28 \mathrm{~d}$ in QUV.

The other dual-coated system tested is based on FRC 6 associated with top-coating D. Table 9 shows results before and after accelerated-weathering using the cone calorimeter for system 6+D.

Table 9. Cone calorimetry results of system $\mathbf{6}+\mathbf{D}$ before and after aging in the QUV. Sample 6 and Sample D values are reported as $\bar{x} \pm 1 \sigma$ calculated from 10 replicant measurements from 5 samples. All other values are from testing of a single sample.

\begin{tabular}{|c|c|c|c|c|c|c|c|c|}
\hline Sample & $\begin{array}{l}\text { TTI } \\
\text { (s) }\end{array}$ & $\begin{array}{l}\text { TTFO } \\
\text { (s) }\end{array}$ & $\begin{array}{c}1^{\text {st }} \text { PHRR } \\
\left(\mathrm{kW} / \mathrm{m}^{2}\right)\end{array}$ & $\begin{array}{c}2^{\text {nd }} \text { PHRR } \\
\left(\mathrm{kW} / \mathrm{m}^{2}\right)\end{array}$ & $\begin{array}{l}1^{\text {st }} \text { tPHRR } \\
\text { (s) }\end{array}$ & $\begin{array}{l}2^{\text {nd }} \text { tPHRR } \\
\text { (s) }\end{array}$ & $\begin{array}{c}\text { THR } \\
\left(\mathbf{M J} / \mathbf{m}^{2}\right)\end{array}$ & $\begin{array}{c}\text { Residue } \\
\text { (mass \%) }\end{array}$ \\
\hline 6 & $\mathrm{~N} / \mathrm{A}^{\mathrm{a}}$ & $\mathrm{N} / \mathrm{A}$ & $\mathrm{N} / \mathrm{A}$ & $\mathrm{N} / \mathrm{A}$ & $\mathrm{N} / \mathrm{A}$ & $\mathrm{N} / \mathrm{A}$ & $\mathrm{N} / \mathrm{A}$ & N/A \\
\hline D & $20 \pm 1$ & $678 \pm 35$ & $338.4 \pm 2.7$ & $131.1 \pm 5.2$ & $44 \pm 0$ & $496 \pm 13$ & $57.2 \pm 2.8$ & $23.8 \pm 1.1$ \\
\hline \multicolumn{9}{|l|}{$6+D$} \\
\hline$t_{0 d}$ & 24 & 54 & 203.1 & N/A & 48 & N/A & 3.6 & 97.2 \\
\hline $\mathbf{t}_{1 \mathrm{~d}}$ & 25 & 55 & 208.6 & N/A & 49 & N/A & 3.9 & 97.7 \\
\hline$t_{3 d}$ & 29 & 60 & 219.9 & N/A & 50 & N/A & 3.8 & 97.1 \\
\hline$t_{7 d}$ & 29 & 767 & 189.9 & 120.5 & 53 & 606 & 52.1 & 32.5 \\
\hline
\end{tabular}

${ }^{\mathrm{a} N o}$ ignition

Again, the use of top-coating $\mathbf{D}$ with FRC 6, $(6+D)_{0}$, presents good results in terms of coatings compatibility and flaming behavior. Indeed, the same observations regarding system $\mathbf{1}+\mathbf{D}$ can be made; compared to FRC 6 itself, system 6+D ignites with a higher $1^{\text {st }}$ PHRR due to the layer of acrylic fuel, but the intumescent expansion from coating $\mathbf{6}$ allows self-extinguishment within $30 \mathrm{~s}$, which also explains a small value of THR (around $4 \mathrm{MJ} / \mathrm{m}^{2}$ ). Surprisingly, those results remain the same after $3 \mathrm{~d}$ in the QUV regarding the degradation of the coating film after $1 \mathrm{~d}$ (cracking, yellowing - Fig. 6). But, after $7 \mathrm{~d}$ in the QUV, the sample ignited and extinguished 
after almost $800 \mathrm{~s}$ with results in terms of PHRR and THR closed to uncoated red cedar. The system 6+D lasted between $3 \mathrm{~d}$ and $7 \mathrm{~d}$ in the accelerated-weathering QUV device which would correlate to an average of 50 days outside. The top-coating failure may have been earlier for FRC 6 due to slightly worse compatibility of the two coatings.

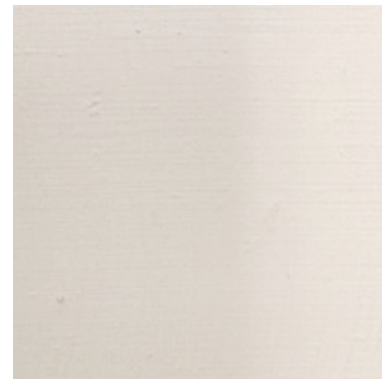

$t_{0 d}$

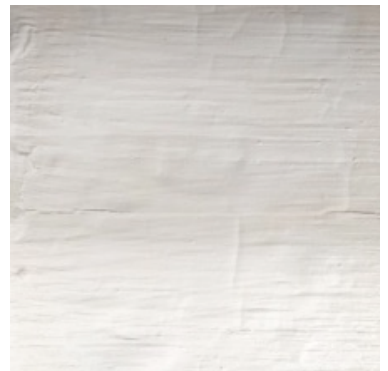

$t_{1 d}$

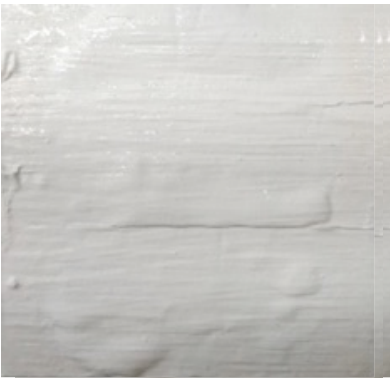

$\mathrm{t} 3 \mathrm{~d}$

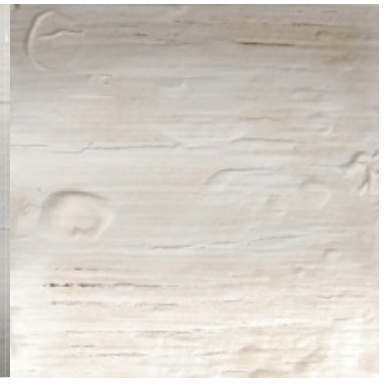

$\mathrm{t} 7 \mathrm{~d}$

Fig. 6. Aging of system 6+D after $7 \mathrm{~d}$ in the QUV.

Only two systems (fire-retardant and top-coating) are compatible: $\mathbf{1}+\mathbf{D}$ and $\mathbf{6}+\mathbf{D}$. They both present good flammability resistance regarding cone calorimetry results. However, by performing aging experiments using accelerated-weathering QUV device, systems 1+D and 6+D are predicted to last for an average of respectively 7 months and 50 days outside.

Currently, coating manufacturers are using several standard fire tests for construction/building materials, such as ASTM E84 [54], and ATME E119 [55] to evaluate the fire performances of their FRCs. Few information is available regarding the way they are aging their coated samples, but companies would mostly ran the UL 263 test [56]. By comparing this methodology to the one from this study, two main problems can arise. The first one relates to the use of different substrates. Some companies will test their FRCs on steel plates which prevents water infiltration and therefore the acceleration of aging as observed with red cedar wood substrate. The second one concerns the use of different fire tests which might present lower radiation exposure (heat flux) than the cone calorimeter.

As a result, FRCs tested in this study all showed limited performance in terms of durability. Realistically, it is unlikely that homeowners would reapply coatings every seven months to insure fire protection of their exterior wood-based materials. We then believe that potential FRCs users should review manufacturer's fire test data after weathering, to confirm the expected service life for exterior applications.

\section{Conclusions}

A limited number of commercial fire-retardant coatings (FRCs), either film-forming or nonfilm forming (stains) for exterior application, and dual-coated wood systems comprising of FRC plus weather-resistant a top-coating were characterized and tested for their fire performance. They were evaluated by microscale combustion calorimetry and cone calorimetry $\left(50 \mathrm{~kW} / \mathrm{m}^{2}\right)$ before and after weathering. Of the ten commercial coatings, four film-forming FRCs showed acceptable results: even though they all showed lower THR over time, only two coatings did not ignite at all and two others did ignite, but self-extinguished within $15 \mathrm{~s}$ due to the intumescent char expansion. An accelerated-weathering QUV device was used to predict the natural weathering (humid subtropical) of these FRCs on wood. Aging experiments showed that the four best FRCs will only last a few weeks outside before losing 
their fire protection capabilities. Thereby, five top-coatings were selected to improve weatherability; but only two showed good rainwater solubility results and were applied on top of the 4 FRCs ( 8 dual-coated systems in total). Only two dual-coated systems were compatible and thereby tested for fire behavior and weathering resistance. They both showed good fire retardancy properties; both systems ignited but self-extinguished within $40 \mathrm{~s}$ due to the expansion of the intumescent underlayer resulting in the reduction of PHRR and THR values as compared to uncoated red cedar wood. Using the QUV to assess their weathering resistance, an outdoor durability of up to seven months was estimated. Due to the limited performance after weathering, it is recommended that potential FRCs users should review manufacturer's fire test data after weathering, to confirm the expected service life for exterior applications.

\section{Acknowledgements}

This work was supported by NIST, United States. The authors would like to thank John Shields, Andre Thompson and Olivia Hernandez for their assistance and suggestions with the experiments. Special thanks to Kathryn Butler, Alexander Maranghides, Erik Johnsson, and Douglas Fox for the useful discussions during this project.

\section{References}

[1] R. Rasker, Communities Threatened by Wildfires, 2000-2017, Headwaters Economics, 2018.

[2] D.S. Thomas, D.T. Butry, S.W. Gilbert, D.H. Webb, J.F. Fung, The Costs and Losses of Wildfires, NIST Special Publication 1215 (2017).

[3] Top 20 most destructive California wildfires; California Department of Forestry and Fire Protection, 2019.

[4] S.L. Manzello, S.H. Park, T.G. Cleary, Investigation on the ability of glowing firebrands deposited within crevices to ignite common building materials, Fire Saf. J. 44(6) (2009) 894900.

[5] S.L. Manzello, J.R. Shields, T.G. Cleary, J.C. Yang, Ignition of Mulch by Firebrands in Wildland/Urban Interface (WUI) Fires, International Symposium on Fire and Forest Meterology, Alberta, CA, 2005.

[6] V. Babrauskas, Ignition handbook, Process Saf. Environ. Prot. 83(B3) (2005) 275.

[7] S.L. Quarles, C.D. Standohar-Alfano, Ignition Potential of Decks Subjected to an Ember Exposure, Insurance Institute for Business and Home Safety, 2017.

[8] A.C. Fernandez-Pello, Wildland fire spot ignition by sparks and firebrands, Fire Safety Journal 91 (2017) 2-10.

[9] E. Koo, P.J. Pagni, D.R Weise, J.P. Woycheese, Firebrands and spotting ignition in largescale fires, International Journal of Wildland Fire 19(7) (2010) 818-843.

[10] E.L. Johnsson, A. Maranghides, Effects of Wind Speed and Angle on Fire Spread along Privacy Fences, National Institute of Standards \& Technology, 2016.

[11] Quadrennial Fire Review, National Association of State Foresters, 2009.

[12] V. Butsic, M. Kelly, M. Moritz, Land Use and Wildfire: A Review of Local Interactions and Teleconnections, 2015.

[13] V. Spyratos, P.S. Bourgeron, M. Ghil, Development at the wildland-urban interface and the mitigation of forest-fire risk, Proceedings of the National Academy of Sciences 104(36) (2007) 14272. 
[14] R. Rasker, The Wildland-Urban Interface: The Problem, Trends and Solutions, Headwaters Economics, 2018.

[15] J.L. Pellegrino, N.P. Bryner, E.L. Johnsson, Wildland-Urban Interface Fire Research Needs, NIST Special Publication 1150 (2013).

[16] G. Broyles, Structure Protection Materials Evaluation, United States Department of Agriculture (2014).

[17] B. Bahrani, V. Hemmati, A. Zhou, S.L. Quarles, Effects of natural weathering on the fire properties of intumescent fire-retardant coatings, Fire Mater. 42(4) (2018) 413-423.

[18] B. Müller, U. Poth, Coatings Formulation, An International Textbook, 2017.

[19] R. Puri, A. Khanna, Intumescent coatings: A review on recent progress, Journal of Coatings Technology and Research 14 (2016).

[20] H.L. Vandersall, Intumescent coating systems, their development and chemistry, J. Fire Flammability 2 (1971) 97-140.

[21] H.L. Vandersall, Intumescent coating systems, their development and chemistry, J. Fire Flammability 2 (1971) 97-140.

[22] S. Bourbigot, S. Duquesne, Fire retardant polymers: Recent developments and opportunities, J. Mater. Chem. 17(22) (2007) 2283-2300.

[23] M. Wladyka-Przybylak, R. Kozlowski, The thermal characteristics of different intumescent coatings, Fire Mater. 23(1) (1999) 33-43.

[24] B. Ostman, A. Voss, A. Hughes, P J. Hovde, O. Grexa, Durability of fire retardant treated wood products at humid and exterior conditions. Review of literature, Fire Mater. 25(3) (2001) 95-104.

[25] ASTM, D2369-10 Standard Test Method for Volatile Content of Coatings, ASTM International, West Conshohocken, PA, 2015.

[26] ASTM, D1475-13 Standard Test Method For Density of Liquid Coatings, Inks, and Related Products, West Conshohocken, PA, 2013.

[27] ASTM, D792-13 Standard Test Methods for Density and Specific Gravity (Relative Density) of Plastics by Displacement, West Conshohocken, PA, 2012.

[28] OG202 Paint Inspection Gauge. http://www.micro-metrics.com/og202.htm.

[29] Govmark MCC-1. https://www.govmark.com/testing-instruments/MicroscaleCombustion-Calorimeter.

[30] R.E. Lyon, R.N. Walters, A Mircoscale Combustion Calorimeter, Federal Aviation Administration, 2002.

[31] Cone Calorimeter. https://www.fire-testing.com/icone-mini-and-icone-classiccalorimeters/.

[32] ASTM, E1354-17 Standard Test Method for Heat and Visible Smoke Release Rates for Materials and Products Using an Oxygen Consumption Calorimeter, West Conshohocken, PA, 2017.

[33] ASTM, D3132 Standard Test Method for Solubility Range of Resins and Polymers, West Conshohocken, PA, 1996.

[34] W.F. Koch, G. Marinenko, R.C. Paule, Development of a standard reference material for rainwater analysis, J. Res. Natl. Bur. Stand. (U. S.) 91(1) (1986) 33-9.

[35] QUV Accelerated Weathering Tester. https://www.q-lab.com/products/quv-weatheringtester/quv.

[36] ASTM, G154-16 Standard Practice for Operating Fluorescent Ultraviolet (UV) Lamp Apparatus for Exposure of Nonmetallic Materials, West Conshohocken, PA, 2016. 
[37] R.E. Lyon, R.N. Walters, Pyrolysis combustion flow calorimetry, J. Anal. Appl. Pyrolysis 71(1) (2004) 27-46.

[38] R. Sonnier, H. Vahabi, L. Ferry, J.M. Lopez-Cuesta, Pyrolysis-combustion flow calorimetry: a powerful tool to evaluate the flame retardancy of polymers, ACS Symp. Ser. 1118(Fire and Polymers VI) (2012) 361-390.

[39] R.E. Lyon, R.N. Walters, S.I. Stoliarov, Screening flame retardants for plastics using microscale combustion calorimetry, Polym. Eng. Sci. 47(10) (2007) 1501-1510.

[40] R. Sonnier, L. Ferry, C. Longuet, F. Laoutid, B. Friederich, A. Laachachi, J.M. LopezCuesta, Combining cone calorimeter and PCFC to determine the mode of action of flameretardant additives, Polym. Adv. Technol. 22(7) (2011) 1091-1099.

[41] H.E. Anderson, Heat Transfer and Fire Spread, USDA Forest Service, 1969.

[42] P. Rantuch, I. Hrusovsky, J. Martinka, K. Balog, S. Hirle, Determination of the Critical Heat Flux for Floating Flooring, Wood Research 6(62) (2017) 973-982.

[43] M.J. Spearpoint, J.G. Quintiere, Predicting the piloted ignition of wood in the cone calorimeter using an integral model - effect of species, grain orientation and heat flux, Fire Safety Journal 36(4) (2001) 391-415.

[44] B. Schartel, T.R. Hull, Development of fire-retarded materials-Interpretation of cone calorimeter data, Fire and Materials 31(5) (2007) 327-354.

[45] L. Podgorski, M. Arnold, G. Hora, A reliable artificial weathering test for Wood Coatings, 2003.

[46] R.A. Wade, Accelerated Weathering of Wood Coatings by QUV-A with Direct Water Spray, Bayer Material Science, 2009.

[47] Q. Xu, G.Q. Li, J. Jiang, Y.C Wang, Experimental study of the influence of topcoat on insulation performance of intumescent coatings for steel structures, Fire Safety Journal 101 (2018) 25-38.

[48] M. Jimenez, S. Bellayer, A. Naik, P. Bachelet, S. Duquesne, S. Bourbigot, Topcoats versus Durability of an Intumescent Coating, Ind. Eng. Chem. Res. 55(36) (2016) 9625-9632. [49] T. Mariappan, A. Kamble, S.M. Naik, An investigation of primer adhesion and topcoat compatibility on the waterborne intumescent coating to structural steel, Progress in Organic Coatings 131 (2019) 371-377.

[50] C-E. Wilen, R. Pfaendner, Improving weathering resistance of flame-retarded polymers, J. Appl. Polym. Sci. 129(3) (2013) 925-944.

[51] A. Cogulet, P. Blanchet, V. Landry, Evaluation of the impacts of fourweathering methods on two acrylic paints: showcasing distinctions and particularities, Coatings 9(2) (2019) 121/1$121 / 13$.

[52] M.J. Melo, S. Bracci, M. Camaiti, O. Chiantore, F. Piacenti, Photodegradation of acrylic resins used in the conservation of stone, Polymer Degradation and Stability 66(1) (1999) 2330.

[53] D.M. Fox, Personal Communication, 2019.

[54] ASTM, E84-19b Standard Test Method for Surface Burning Characteristics of Building Materials, West Conshohocken, PA, 2019.

[55] ASTM, E119-18ce1 Standard Test Methods for Fire Tests of Building Construction and Materials, West Conshohocken, PA, 2018.

[56] UL, UL263 Standard for Fire Tests of Building Construction and Materials, 2018. 


\section{Appendix A: Supplemental Materials}

Microscale Combustion Calorimetry:

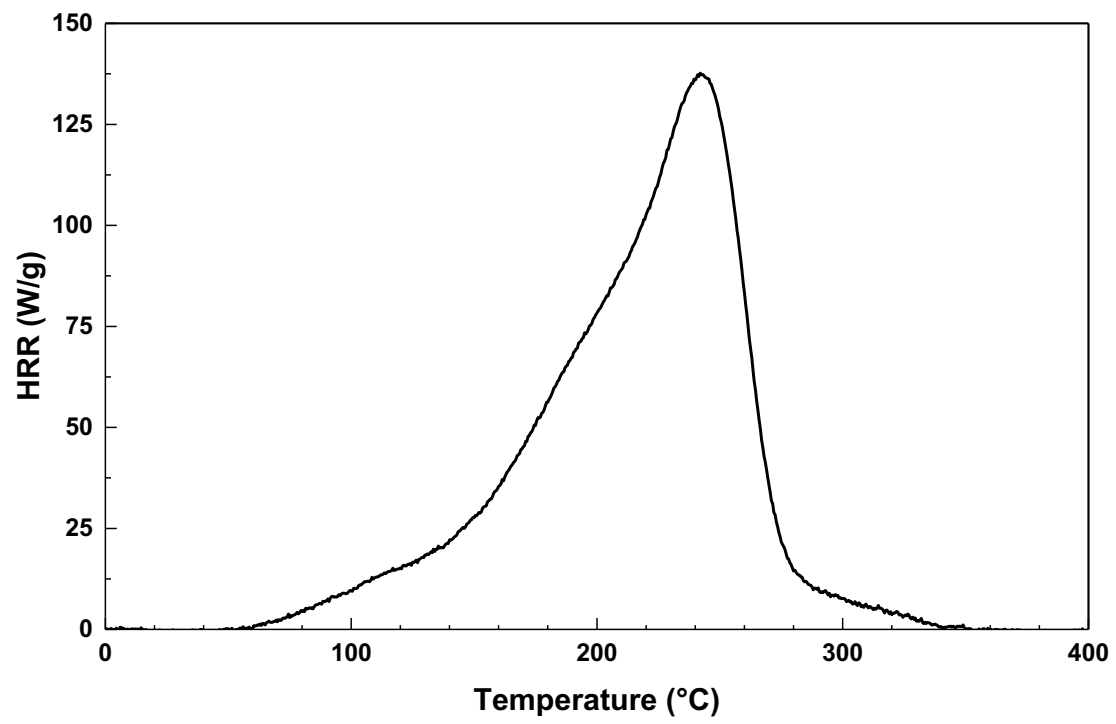

Fig. 7. HRC as a function of time for uncoated red cedar using MCC.

Cone calorimetry:
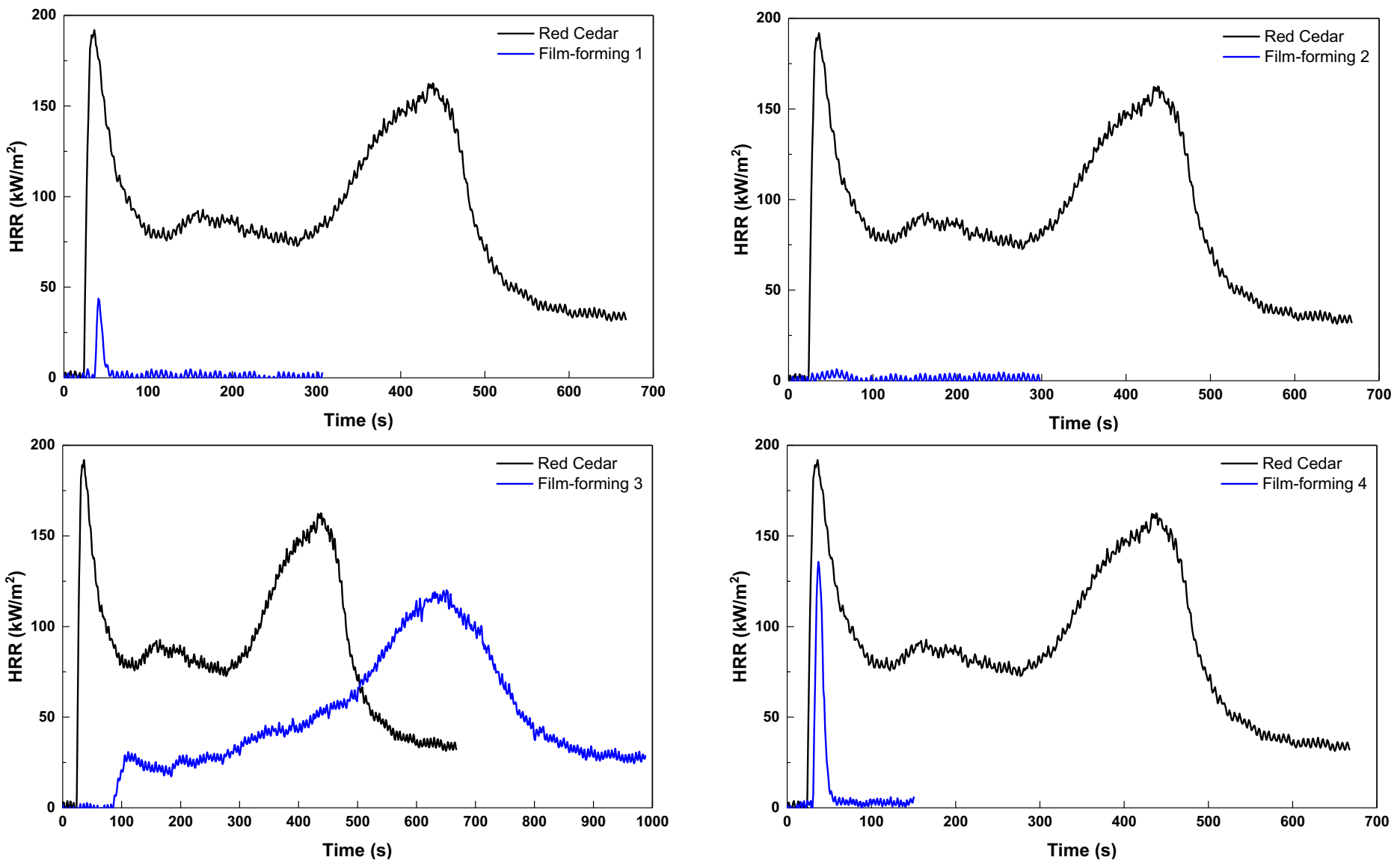

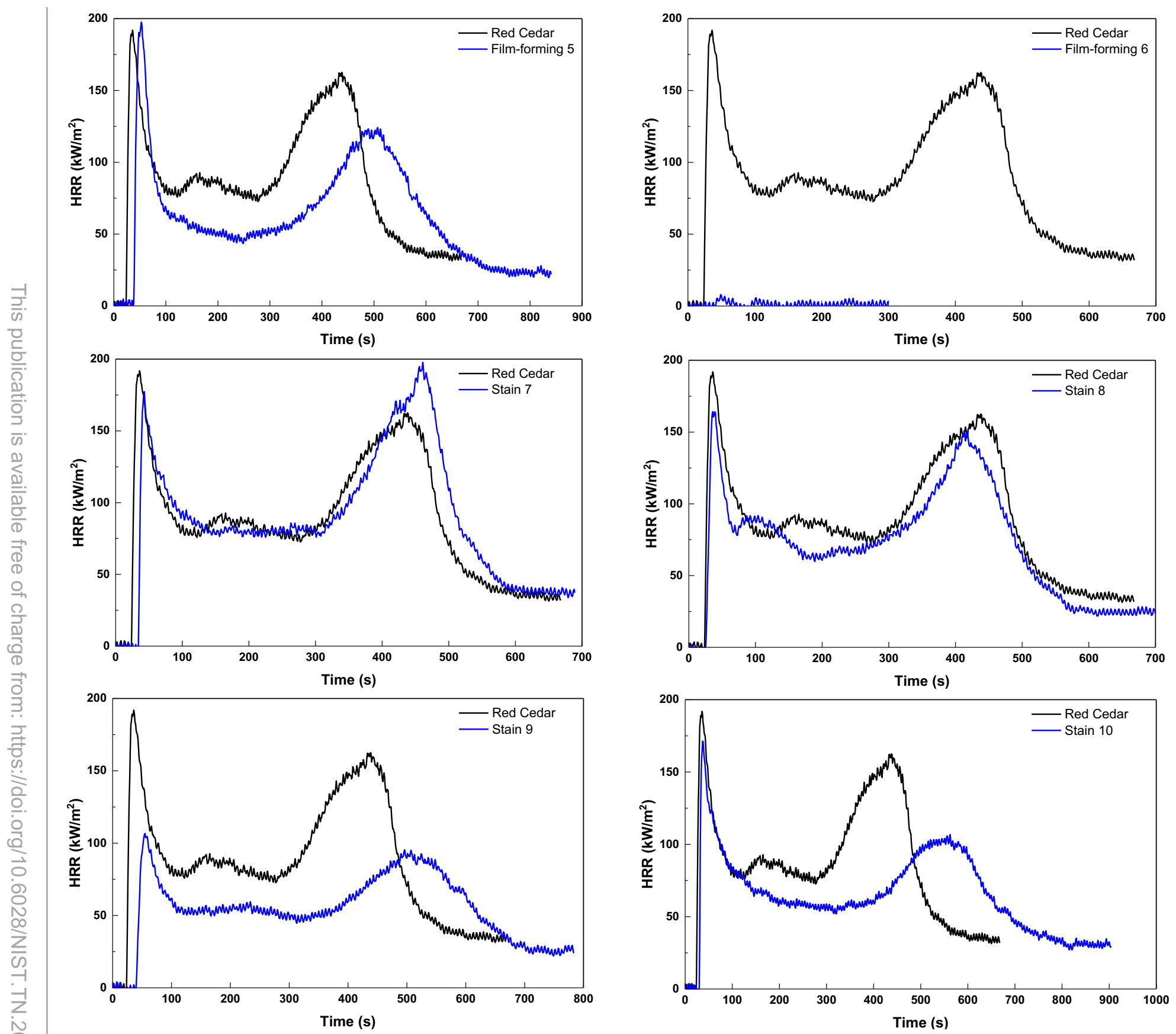

Fig. 8. HRR as a function of time for all commercial FRCs (film-forming and stains). 

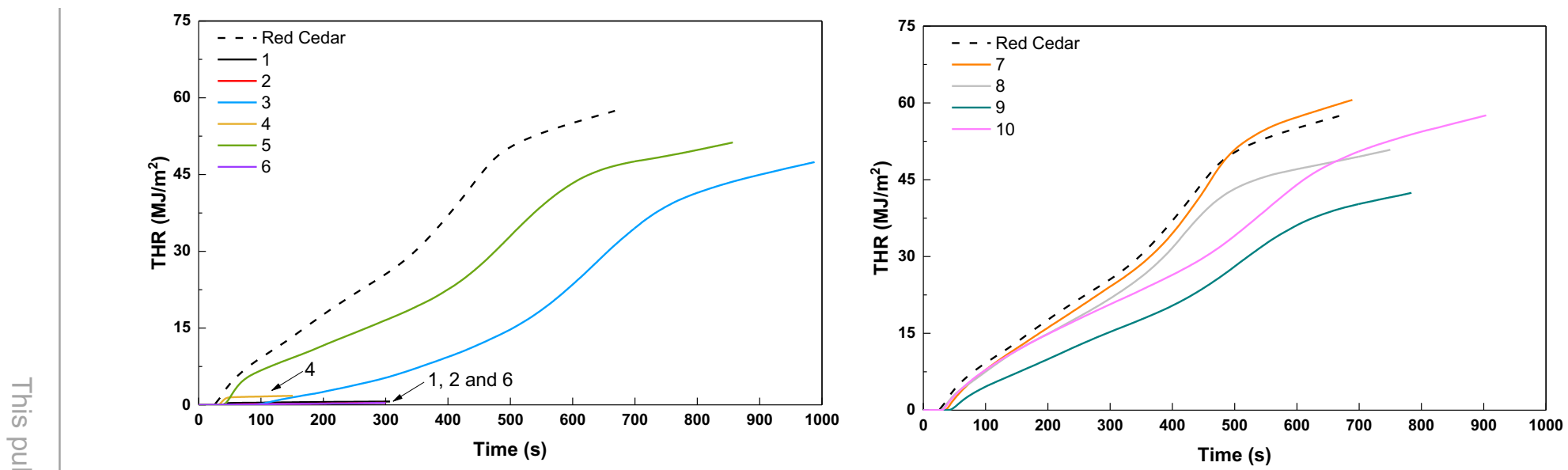

Fig. 9. THR as a function of time for all commercial FRCs (film-forming and stains).

Incompatibility between FR coatings and top-coatings:
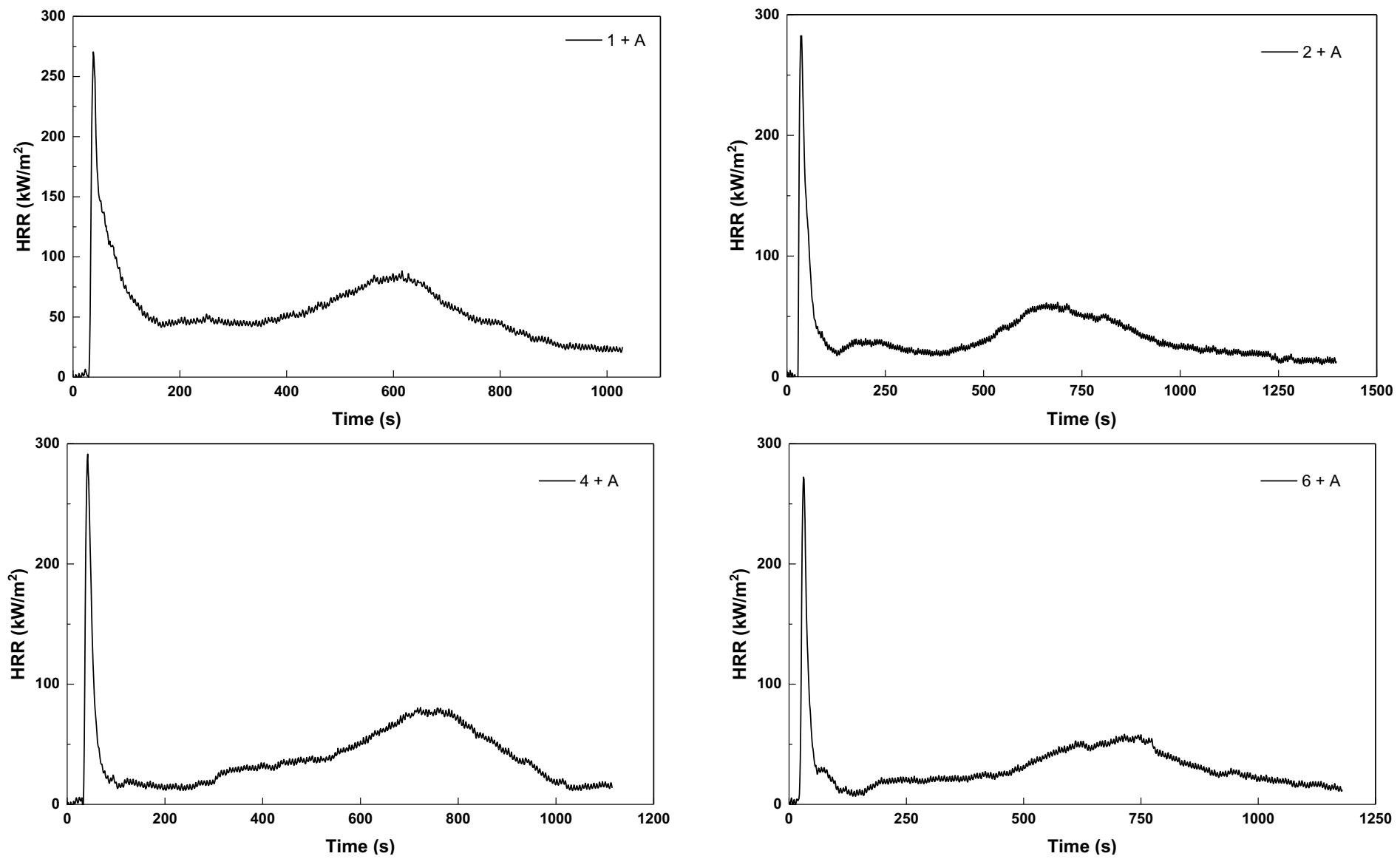

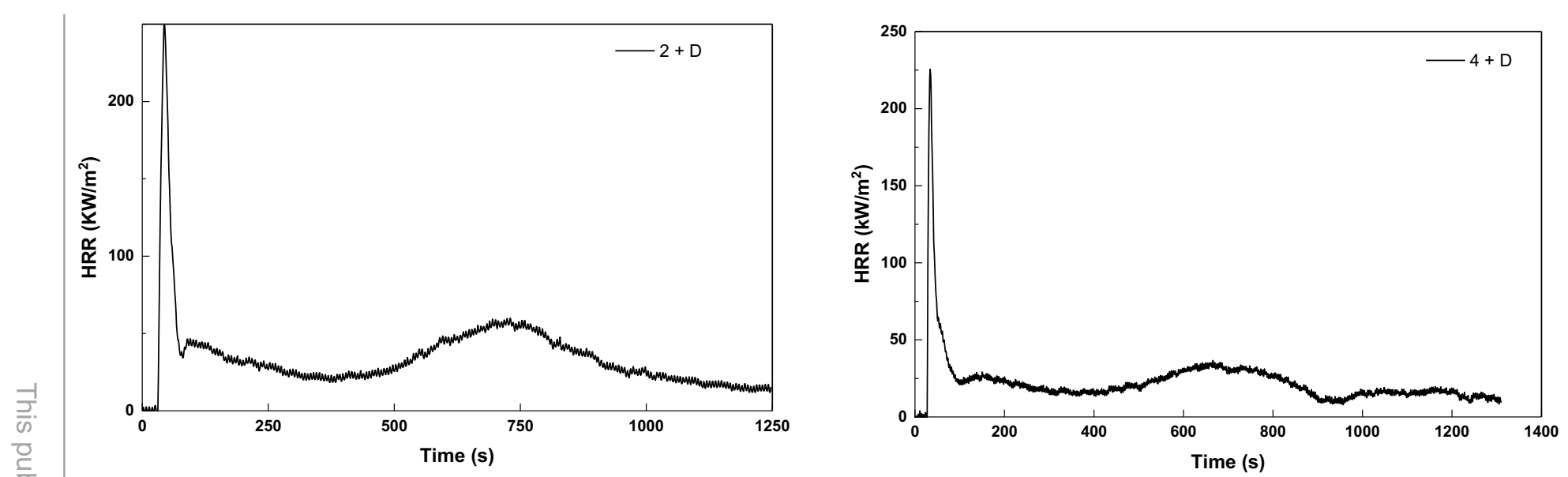

Fig. 10. HRR as a function of time for incompatible FRC + top-coating dual-coated systems.

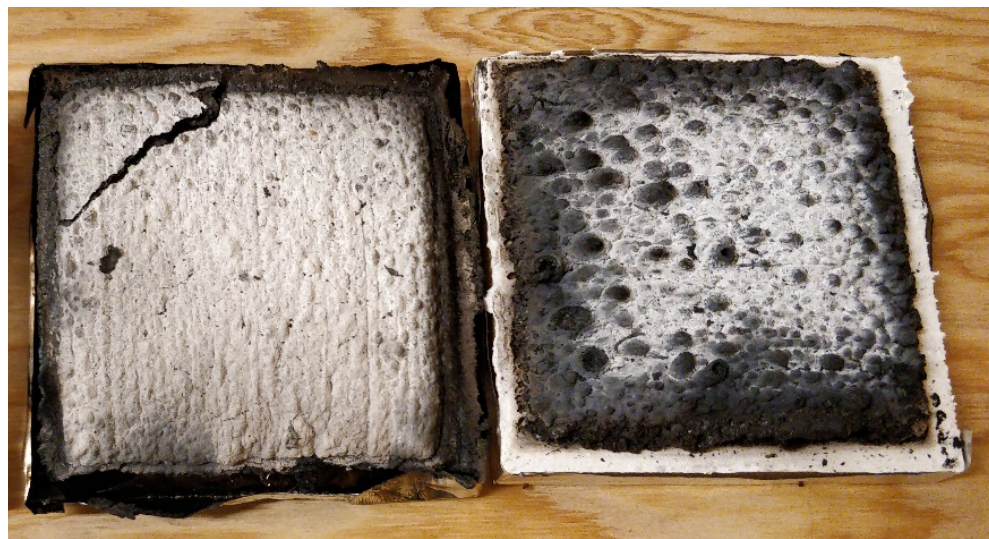

Fig. 11. System 2+D (left) and 1+D (right). The intumescent char expansion from FRC 1 protected the wood substrate. The incompatibility between $\mathbf{2}$ and $\mathbf{D}$ suppressed the fire protection.
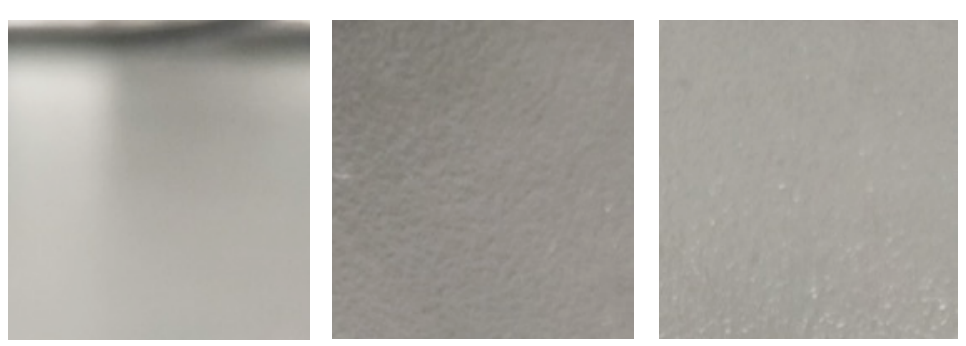

Fig. 12. Intumescent char expansion $(\mathbf{2}$ - left), reduction $(\mathbf{2}+\mathbf{D}$ - middle), suppression (4+D right), after MCC experiments. 